\title{
Article
}

\section{Influence of Organoclay Content on the Structure, Morphology and Surface Related Properties of Novel Poly(dimethylsiloxane)- based Polyurethane/Organoclay Nanocomposites}

\author{
Marija Vuk Pergal, Ivan S. Stefanovi\#, Rafal Poreba, Miloš \\ Steinhart, Petar M. Jovancic, Sanja Ostoji\#, and Milena Spirkova \\ Ind. Eng. Chem. Res., Just Accepted Manuscript • DOI: 10.1021/acs.iecr.6b04913 • Publication Date (Web): 12 Apr 2017 \\ Downloaded from http://pubs.acs.org on April 14, 2017
}

\section{Just Accepted}

"Just Accepted" manuscripts have been peer-reviewed and accepted for publication. They are posted online prior to technical editing, formatting for publication and author proofing. The American Chemical Society provides "Just Accepted" as a free service to the research community to expedite the dissemination of scientific material as soon as possible after acceptance. "Just Accepted" manuscripts appear in full in PDF format accompanied by an HTML abstract. "Just Accepted" manuscripts have been fully peer reviewed, but should not be considered the official version of record. They are accessible to all readers and citable by the Digital Object Identifier (DOI®). "Just Accepted" is an optional service offered to authors. Therefore, the "Just Accepted" Web site may not include all articles that will be published in the journal. After a manuscript is technically edited and formatted, it will be removed from the "Just Accepted" Web site and published as an ASAP article. Note that technical editing may introduce minor changes to the manuscript text and/or graphics which could affect content, and all legal disclaimers and ethical guidelines that apply to the journal pertain. ACS cannot be held responsible for errors or consequences arising from the use of information contained in these "Just Accepted" manuscripts. 
Influence of Organoclay Content on the Structure, Morphology and Surface Related Properties of Novel Poly(dimethylsiloxane)-based Polyurethane/Organoclay Nanocomposites

Marija V. Pergal, ,a, Ivan S. Stefanović, ${ }^{a}$ Rafał Poręba, ${ }^{\text {b }}$ Miloš Steinhart, ${ }^{c}$ Petar Jovančić, Sanja Ostojiće ${ }^{\mathrm{e}}$ and Milena Špírkováb

${ }^{a}$ Institute of Chemistry, Technology and Metallurgy (ICTM) - Center of Chemistry, University of Belgrade, Njegoševa 12, 11000 Belgrade, Serbia;

${ }^{\mathrm{b}}$ Institute of Macromolecular Chemistry AS CR, v.v.i. (IMC), Heyrovsky Sq. 2, 16206 Prague 6, Czech Republic;

${ }^{\mathrm{c}}$ Institute of Applied Physics and Mathematics, Faculty of Chemical Technology, University of Pardubice, Studentska 95, 53210 Pardubice, Czech Republic;

${ }^{\mathrm{d}}$ Faculty of Technology and Metallurgy, University of Belgrade, Karnegijeva 4, 11000 Belgrade, Serbia;

${ }^{\mathrm{e}}$ Institute of General and Physical Chemistry, University of Belgrade, Studentski trg 12-16, 11000 Belgrade, Serbia.

*Corresponding author. E-mail: marijav@chem.bg.ac.rs 


\begin{abstract}
Novel poly(dimethylsiloxane)-based polyurethane nanocomposites (TPU-NCs) were synthesized using in situ polymerization with the nanoclay, Cloisite 30B. DSC, TGA and DMTA analyses showed that TPU-NCs with organoclay content $\leq 5 \mathrm{wt} \%$ exhibited increased thermal stability, storage modulus and hard segment melt temperatures, but decreased degrees of crystallinity. TPU-NCs displayed increased surface hydrophilicity and enhanced surface free energy with increasing organoclay content. SWAXS confirmed intercalated formations of organoclays in the nanocomposites. Individual clay particles on surfaces of TPUs with lower organoclay loadings ( 1 or $3 \mathrm{wt} \%$ ), or organoclay agglomerates in TPUs with higher amounts of organoclay ( $\geq 5 \mathrm{wt} \%$ ) were detectable using SEM. The relatively smooth and homogeneous character of pure TPU and the distinctly heterogeneous and rough surfaces of TPU-NCs were detected via AFM. Among the nanomaterials prepared, TPU-NC with 1 wt \% of organoclay provided the best balance between organoclay concentration and the functional properties desired in biomedical applications.
\end{abstract}

Keywords: Polyurethanes; Poly(dimethylsiloxane); Polymer-matrix composites; Layered silicates; Surface properties. 


\section{Introduction}

Thermoplastic polyurethane elastomers (TPUs) are multiblock copolymer materials ${ }^{1-4}$ and can possess properties that enhance their candidacy for use in biomedical devices. ${ }^{4}$ They contain soft segments that are interspersed with hard segments in a regular manner. ${ }^{1,4}$ Phase separation can be caused by the hard and soft segments having incompatible thermodynamic properties, which subsequently means they become organized into hard and soft domains mostly on the nanometer scale, and because of which, TPUs acquire their distinct mechanical properties and thermoplastic utility. ${ }^{1-4}$ TPUs based on a soft segment of poly(dimethylsiloxane) (PDMS) possess lower glass transition temperatures, higher thermal and thermo-oxidative stability, are more resistant to atomic oxygen, ozone and ultraviolet wavelengths, have excellent hydrophobicity, are biocompatible, are more permeable to many gases and are resistant to more solvents than conventional polyurethanes, which are polyether- or polyester-based. ${ }^{5,6}$ PDMS-based TPUs have good biostability and blood-contacting characteristics. This contrasts with conventional TPUs, the soft segments (polyether- or polyester-based) of which can oxidatively and hydrolytically degrade when the materials are used in vivo. ${ }^{5-7}$ Therefore, the role of conventional TPUs in biomedical implants is very restricted. ${ }^{5-7}$

Polyurethane-layered silicate nanocomposites (TPU-NCs) have received much interest from industry and academia recently, since they can have more desirable physical and chemical characteristics than pure TPUs. ${ }^{9-14}$ Their outstanding thermal, mechanical and especially barrier performances, realized even when nanofiller levels are less than $5 \mathrm{wt} \%$, are the result of physical and chemical interphase interactions. ${ }^{15}$ Namely, TPU-NCs are now studied with the aim of enhancing their biostability and other properties, thereby increasing their potential for application in implants. ${ }^{4}$ Organoclay dispersion to nanoscale layers (exfoliation) inside polymer matrices is difficult to attain, due to the hydrophobic polymers being incompatible with the hydrophilic organoclays. However, such dispersion has an important role in improving the products' properties. To increase silicate's compatibility with the polymer, clay nanolayers are altered using hydrophobic surfactants, so that metal ions are replaced with organic long-chain cations like alkylammonium ions. ${ }^{16}$ Additionally, organoclays which are altered in this way can play a role in the polymerization itself, so that exfoliated silicate arrangements occur in the polymer. ${ }^{17-19}$ 
Also, it was reported that chains of polymers can be intercalated into spaces between layers. ${ }^{4}$ This can produce a more orderly morphology and some layers of clay being in dispersed stacks, which in turn produced improvements of the TPUs' characteristics. ${ }^{4}$ Nanoscale dispersion of clays in TPUs and characteristics of TPU nanocomposites are contingent on the steps in their manufacture, the amounts and types of hard and soft segments, and the amount, chemical properties and structure of the organoclay, as well as intensity of interfacial interactions of the polymer substrate with the organoclay. ${ }^{20-25}$ Jeong et al. $^{26}$ and Meng et al. ${ }^{27,28}$ showed the microphase separation and degree of improvement to thermal and mechanical properties are mainly reliant on the degree of dispersion that occurs when nanoparticles are incorporated in polymer substrates. Some recent studies revealed that TPU nanocomposites have the potential to be developed for biomedical device components because of their enhanced mechanical, barrier and thermal properties ${ }^{4,29}$ and their capability in tuning cell-material interactions. ${ }^{4}$ The possibility of PDMS-based TPU-NCs being used in biomedicine was recently reported by Osman et al. ${ }^{30,31}$ They determined that 2 wt \% of low aspect ratio organosilicate dispersed thoroughly in their PDMS-based TPU matrix, and they also found that level produced extra hard domain connectivity compared to higher filler loadings (4 wt \%), thereby enhancing the material's mechanical and thermal properties. ${ }^{30}$

We previously studied the fabrication of PDMS-based TPUs as well as their characterization and biocompatibility assessment, and confirmed that the chemical structure and amounts of the soft PDMS segments have a predominant influence on the surface, thermal, thermomechanical and biocompatible characteristics of PDMS-based TPUs. ${ }^{32-36}$ We have found that good hemoand cyto-compatibility is related to higher surface roughness, better microphase separation structure, and higher hydrophilicity of these TPUs.

Owing to our interest in developing new materials with improved properties for potential biomedical application, the aim of this work was to investigate the effect of nano-scale organoclay on the thermal, thermomechanical, surface and morphological properties of PDMSbased TPU hybrid materials. Nanocomposites with various organoclay levels (from 1-10 wt \%) were synthesized using in situ polymerization of TPU, and using hydroxyethoxy-propylterminated PDMS as the matrix, while Cloisite 30B was used as the nanoclay. To our knowledge, data are lacking on the preparation and characterization of TPU nanocomposites based on only ethoxypropyl-PDMS as the soft segment, even though this very species of TPU-NC is a very 
attractive material for biomedical applications. Nanoscale dispersion of Cloisite 30B in TPU-NCs was evaluated by SEM and AFM analyses, while the structural, thermal, thermomechanical and surface properties were monitored by FTIR, SWAXS, DSC, TGA, DMTA, and water contact angle measurements, respectively.

\section{Experimental section}

2.1. Materials. $\alpha, \omega$-Dihydroxyethoxy-propyl-poly(dimethylsiloxane) (EO-PDMS, $>99 \%$ ) was prepared by recovery from ABCR. Prior to use, EO-PDMS was subjected to drying with the use of molecular sieve $(0.4 \mathrm{~nm}$; Aldrich), and structure and molecular weight of EO-PDMS macrodiols were then determined and calculated using ${ }^{1} \mathrm{H}$ NMR spectroscopy: the PDMS-block had an average polymerization degree $=9.95$, while the EO-PDMS macrodiol had a molecular weight (number average) of $1000 \mathrm{~g} / \mathrm{mol}$. 4,4'-Methylenediphenyldiisocyanate (MDI) was obtained from the manufacturer and not subjected to alteration ( $>98 \%$ purity, Aldrich). 1,4Butanediol (BD, 99\%) was obtained from Aldrich, but was then vacuum distilled to improve purity. The clay used (Cloisite 30B [C30B]; Southern Clay Products Inc, Gonzales, TX, USA) was a naturally-occurring montmorillonite clay, but which had been modified by the manufacturer using methyl-tallow-bis-2-hydroxyethyl quaternary ammonium salt. The content of alkylammonium ions (90 $\left.\mathrm{mmol} \mathrm{M}^{+} / 100 \mathrm{~g}\right)$ in the space dividing clay layers was measured using cation exchange capacity (CEC). C30B was dried to remove all moisture as previously described, ${ }^{8,11}$ except that the drying temperature was $25{ }^{\circ} \mathrm{C}$, and the procedure lasted $24 \mathrm{~h}$. Solvents were distilled in our laboratory after purchase: ${ }^{32,35}$ tetrahydrofuran (THF, 98\%; J. T. Baker) and N,N-dimethylacetamide (DMAc, 99\%; Acros,). Stannous octoate ( $\operatorname{Sn}(\mathrm{Oct})_{2}, 98 \%$; Aldrich) was diluted in an anhydrous mixture of DMAc/THF $(1 / 1 \mathrm{v} / \mathrm{v})$ as previously described. ${ }^{35}$

\subsection{Poly(dimethylsiloxane)-based TPU nanocomposite preparation. The PDMS-based} TPU-NCs with $1,3,5,8$ or 10 wt \% organoclay loadings, hereafter called TPU-NC1, TPU-NC3, TPU-NC5, TPU-NC8 and TPU-NC10, respectively, were prepared by in situ polymerization. For comparison purposes, TPU without organoclay, abbreviated as TPU-NC0, was also synthesized using the same procedure (see Table 1 for these materials). TPU-NCs and TPU with $20 \mathrm{wt} \%$ of hard segment content were polymerized using the conditions and equipment described in a 
previous study of ours. ${ }^{32,35}$ In order to prepare $10 \mathrm{wt} \%$ organoclay/solvent dispersion (C30B-D), the proper amount of organoclay was added to the solvent mixture DMAc/THF $(1 / 1 \mathrm{v} / \mathrm{v})$ and mixed on a magnetic stirrer rotating at $1000 \mathrm{rpm}$ for $10 \mathrm{~h}$ (ambient temperature) and for $2 \mathrm{~h}$ at 50 ${ }^{\circ} \mathrm{C}$, then sonicated at $25^{\circ} \mathrm{C}$ for $1 \mathrm{~h}$. In the first reaction step, suitable volumes of C30B-D were then added to the EO-PDMS macrodiol in DMAc/THF solution. This reaction mix was kept in an argon atmosphere at ambient temperature, while stirring for $1 \mathrm{~h}$. MDI was then added, and the temperature of the entire mixture was raised to $40{ }^{\circ} \mathrm{C}$. Polymerization was started by the introduction of catalyst $\mathrm{Sn}(\mathrm{Oct})_{2}$ solution. The first polyaddition stage was conducted while the mix was continuously stirred at $40{ }^{\circ} \mathrm{C}$ for 30 minutes, thus producing NCO-terminated prepolymer $^{35,37}$ (when the theoretical -NCO content reached $5.6 \mathrm{wt} \%$, this was considered as formed). In the second polyaddition stage, BD in DMAc/THF (1/1 v/v) was added one drop at a time to the NCO-terminated prepolymer, ${ }^{35,37}$ and the blend was stirred at $50{ }^{\circ} \mathrm{C}$ for $10 \mathrm{~h}$. Then, the blend was sonicated ( 30 minutes at $25^{\circ} \mathrm{C}$ ) to disperse the organoclays in the final TPU nanocomposites. ${ }^{25}$ The sonicated blend was poured into Teflon molds and dried in an oven at 40 ${ }^{\circ} \mathrm{C}$ for $24 \mathrm{~h}$. Solvent residue was evaporated by drying to constant mass (conditions were vacuum oven $\left.(0.5 \mathrm{mmHg}), 60{ }^{\circ} \mathrm{C}, 24 \mathrm{~h}\right)$ as previously described. ${ }^{25,35}$ Finally, films of the polymerized materials, approximately $0.2 \mathrm{~mm}$ thick, were recovered from their Teflon molds and saved for analysis.

The control TPU/C30B-10 material (with $10 \mathrm{wt} \%$ of C30B) was prepared according to the previously described procedure for TPU-NCs; however, C30B was added at the end of reaction when all -NCO groups had reacted, and just before pouring solution in the Teflon molds. The drying procedure was the same as described above. The purpose for preparation of the control TPU/C30B-10 material was to determine whether any chemical reaction occurred between the $\mathrm{CH}_{2} \mathrm{CH}_{2} \mathrm{OH}$ functional group from clay with the TPU, rather than just physical interactions. This was to determine which of the two possibilities (only physical interactions or chemical and physical interactions) would occur, because there is evidence in the literature that both may be possible. ${ }^{19,24,25}$

2.3. Characterization. FTIR spectra of pure TPU, TPU-NCs and TPU/C30B-10 were obtained using a Nicolet 6700 FTIR spectrometer. Scan parameters were: resolution, $2 \mathrm{~cm}^{-1}$; 
range, 400 to $4000 \mathrm{~cm}^{-1}$; replicates, 64 scans of each material; the spectrometer was used in attenuated total reflection mode, as described previously. ${ }^{37}$

Small-angle and near wide-angle X-ray scattering (SAXS + WAXS = SWAXS) studies were conducted with a 3-pinhole camera (Molmet, now Rigaku), and a multilayer aspherical optics system (Osmic Confocal Max-Flux), to concentrate and monochromatize the beam from an X-ray tube with microfocusing capability (Bede), as described by Špírková et al: ${ }^{38}$ parameters: $45 \mathrm{kV}$; $0.66 \mathrm{~mA}(30 \mathrm{~W})$; wavelength $\lambda=0.154 \mathrm{~nm}$. The camera detector for the WAXS region was described previously, ${ }^{36}$ and the imaging plate was FUJI $(23 \times 25 \mathrm{~cm}, 100 \times 100 \mu \mathrm{m}$ pixels $)$. The scattering dependencies were composed of measurements made at three different sample detector distances so that both the small-angle and the near-wide-angle regions could be probed (SWAXS). The total span of the scattering vector $q=4 \pi \sin (\theta) / \lambda$ was $0.05-36 \mathrm{~nm}^{-1}$. Here, $2 \theta$ is the scattering angle and its maximal value is $41^{\circ}$. Peak positions were obtained by fitting Lorentz or Gauss profiles to the scattering curve, which was then used to determine characteristic lengths $D$, described by Bragg's law: $D=2 \pi / q$.

Materials were freeze-fractured after exposure to liquid nitrogen as previously described ${ }^{39}$ to assess inner arrangements within the materials. Images of fracture faces of the materials were obtained on a scanning electron microscope (SEM; JEOL JSM-6460LV) with a voltage of $20 \mathrm{kV}$ and the pressure of $10^{-5} \mathrm{~Pa}$. Samples of the materials previously cracked in liquid nitrogen were coated with gold alloy to improve conductivity and prevent charging.

Surface heterogeneity and topography of fracture faces were also studied and measured using an atomic force microscope (Dimension Icon, Bruker) in tapping mode. The probe (SSS-NCL, SuperSharp SiliconTM SPM-Sensor) was supplied by NanoSensors ${ }^{\mathrm{TM}}$, Switzerland; spring constant $=35 \mathrm{~N} / \mathrm{m}$; resonant frequency $\approx 170 \mathrm{kHz} .{ }^{40}$ The scans covered areas ranging in size from $1 \times 1 \mu \mathrm{m}^{2}$ to $30 \times 30 \mu \mathrm{m}^{2}$.

Differential scanning calorimetry (DSC) of pure TPU, TPU-NCs and TPU/C30B-10 was conducted using a DSC Q1000, TA Instruments (New Castle, DE USA) as previously described. ${ }^{32,35}$ DSC scan parameters: temperature ramped from -90 at $10{ }^{\circ} \mathrm{C}$ per minute, to reach a final temperature of $230{ }^{\circ} \mathrm{C}$; cooling rate $5{ }^{\circ} \mathrm{C}$ per minute; nitrogen flow rate, $50 \mathrm{~cm}^{3}$ per minute; replication of two scans for each material.

The thermal stability of pure TPU, TPU-NCs and TPU/C30B-10 was tested by thermogravimetric analysis (TGA), which was conducted on a TGA Q500 (TA Instruments) 
analyzer as previously described. ${ }^{32,35}$ TA Instruments Universal analysis software (TA Advantage, Version 4.5A) was used to analyze the DSC and TGA curves obtained.

Dynamic mechanical thermal analysis (DMTA) was conducted using a rheometer (ARES G2 rheometer; TA Instruments) in torsion mode as previously described. ${ }^{37}$ During analysis, temperatures ramped up from $-135{ }^{\circ} \mathrm{C}$ at $3{ }^{\circ} \mathrm{C}$ per minute to a final temperature of $250{ }^{\circ} \mathrm{C}$, and using strain $=0.1 \%, 1 \mathrm{~Hz}$ frequency. The measurements were made with the rheometer using torsion fixture geometry on $6.9 \mathrm{~mm} \times 18.6 \mathrm{~mm} \times 1.0 \mathrm{~mm} \pm 0.2 \mathrm{~mm}$ portions of the materials as previously described. ${ }^{37}$

Static water contact angle (WCA) of pure TPU, TPU-NCs and TPU/C30B-10 was measured as previously described. ${ }^{32,35}$ The surface free energy of TPU and TPU-NCs was calculated according to fundamental equations described by Van Oss et al. $^{41}$, and which are repeated here for clarity only:

$$
\begin{gathered}
\gamma_{L V 1}\left(1+\cos \theta_{1}\right)=2 \sqrt{\gamma_{S}^{L W} \gamma_{L V 1}^{L W}}+\sqrt{\gamma_{S}^{+} \gamma_{L V 1}^{-}}+\sqrt{\gamma_{S}^{-} \gamma_{L V 1}^{+}} \\
\gamma_{L V 2}\left(1+\cos \theta_{2}\right)=2 \sqrt{\gamma_{S}^{L W} \gamma_{L V 2}^{L W}}+\sqrt{\gamma_{S}^{+} \gamma_{L V 2}^{-}}+\sqrt{\gamma_{S}^{-} \gamma_{L V 2}^{+}} \\
\gamma_{L V 3}\left(1+\cos \theta_{3}\right)=2 \sqrt{\gamma_{S}^{L W} \gamma_{L V 3}^{L W}}+\sqrt{\gamma_{S}^{+} \gamma_{L V 3}^{-}}+\sqrt{\gamma_{S}^{-} \gamma_{L V 3}^{+}} \\
\gamma_{S}=\gamma_{S}^{L W}+\gamma_{S}^{A B}=\gamma_{S}^{L W}+2 \sqrt{\gamma_{S}^{+} \gamma_{S}^{-}}
\end{gathered}
$$

In our use of equations (1), $\theta_{1}, \theta_{2}$ and $\theta_{3}$ are the contact angles of distilled water, formamide and diiodomethane on the surface of TPU and TPU-NCs, respectively. $\gamma_{\mathrm{s}}, \gamma^{\mathrm{LW}}, \gamma^{\mathrm{AB}}$ are the surface free energy, dispersion component and polar component, respectively. ${ }^{42} \gamma^{+}$and $\gamma^{-}$are the Lewis acid and Lewis base parameters of the surface free energy, respectively. ${ }^{43,44} \gamma_{\mathrm{LV}}$ is the surface tension of the liquid in equilibrium with its own vapor and subscripts 1,2 and 3 represent liquids 1 (distilled water), 2 (formamide) and 3 (diiodomethane), respectively. ${ }^{44}$ Surface tension values for the various liquids (distilled water, formamide and diiodomethane), needed to solve these equations, were those listed in Khayet et al., Pergal et al., Hwan et al. and Vince et al. ${ }^{45-48}$ Eq. 1 is 
able to be solved, since the values of $\gamma_{L V}^{-}, \gamma_{L V}^{+}$and $\gamma_{L V}^{L W}$ are known; Eq. 1 provides solutions for the total surface free energy $\left(\gamma_{\mathrm{s}}\right)$ and the constituents of $\gamma_{\mathrm{s}}$, which are $\gamma_{S}^{L W}$ and $\gamma_{S}^{A B}$.

\section{Results and discussion}

Novel thermoplastic polyurethane nanocomposites based on ethoxypropyl-terminated PDMS and on $1,3,5,8$ and $10 \mathrm{wt} \%$ of the organoclay Cloisite $30 \mathrm{~B}$ were synthesized using in situ polymerization. The molar ratio of EO-PDMS, MDI and BD was 1:2:1, which resulted in predetermined hard segment content of $20 \mathrm{wt} \%$. The structures of the thermoplastic polyurethanes and organoclay Cloisite $30 \mathrm{~B}$ are shown in Figure 1. Linear polyurethane chains comprise soft segments based on the EO-PDMS macrodiol, alternating with rigid polar hard segments, based on MDI-BD units which have the tendency to order and form semicrystalline structures. In this study, the structure (FTIR, SWAXS, SEM), morphological (AFM), thermal (DSC, TGA), thermomechanical (DMTA), and surface (water contact angle measurements and surface free energy determination) properties of TPU-NCs were analyzed. There are relatively few studies related to the structure-property relationships of poly(urethane-siloxane) nanocomposites based on organoclay nanoparticles in the literature to date. ${ }^{4,30,31}$

\subsection{The Structure, Hydrogen Bonding Formation and Morphological Characterization of TPU-NCs.}

3.1.1. FTIR analysis. FTIR spectroscopy was used to study the microdomain structure of TPUNCs. Figure 2 shows the FTIR spectra of organoclay C30B, control TPU/C30B-10, pure TPU and the TPU-NCs. C30B produced absorption bands at $3625 \mathrm{~cm}^{-1}\left(v_{\mathrm{O}-\mathrm{H}}\right.$, free $), 3335 \mathrm{~cm}^{-1}\left(v_{\mathrm{O}-\mathrm{H}, \mathrm{H}-}\right.$ bonded $), 2926,2850 \mathrm{~cm}^{-1}\left(v_{\mathrm{C}-\mathrm{H}}\right), 1025 \mathrm{~cm}^{-1}\left(v_{\mathrm{C}-\mathrm{O}}\right)$ and $1464\left(\delta_{\mathrm{O}-\mathrm{H}}\right)$. Characteristic bands of pure TPU and TPU-NCs occurred at $3330 \mathrm{~cm}^{-1}\left(v_{\mathrm{N}-\mathrm{H}}\right), 2900$ and $2960 \mathrm{~cm}^{-1}\left(v_{\mathrm{sym}}\right.$ and $v_{\mathrm{asym}}$ of C-H), $1700 \mathrm{~cm}^{-1}\left(v_{\mathrm{C}=\mathrm{O}}\right), 1530$ and $1230 \mathrm{~cm}^{-1}\left(v_{\mathrm{C}-\mathrm{N}}+\delta_{\mathrm{N}-\mathrm{H}}\right.$, i.e., amide II and amide III bands $), 1010$ and $1105 \mathrm{~cm}^{-1}\left(v_{\mathrm{Si}-\mathrm{O}-\mathrm{Si}}\right.$ and $\left.v_{\mathrm{C}-\mathrm{O}-\mathrm{C}}\right), 1410$ and $1590 \mathrm{~cm}^{-1}\left(v_{(\mathrm{C}=\mathrm{C}) \text { arom }}\right)$ and $800 \mathrm{~cm}^{-1}\left(\rho_{\mathrm{C}-\mathrm{H}}\right.$ in $\left.\mathrm{SiCH}_{3}\right)$. Moreover, bands representing organoclay particles, at $520 \mathrm{~cm}^{-1}\left(v_{\mathrm{Si}-\mathrm{O}-\mathrm{Al}}\right)$ and $460 \mathrm{~cm}^{-1}\left(\delta_{\mathrm{Si}-\mathrm{O}-\mathrm{Si}}\right)$, were also observed in our spectral analyses of TPU-NCs. 
Figure 2 shows a small peak only for TPU-NC10 (compared to the other TPU-NCs) at 3625 $\mathrm{cm}^{-1}$, which indicates the presence of structural stretching -OH groups in the organoclay material. The FTIR spectra of control TPU/C30B-10 showed characteristic bands, as in the spectra for TPU-NC10, including the structural stretching -OH groups in the organoclay. In FTIR spectra of all other materials in the series (TPU-NC1 to TPU-NC8), structural stretching -OH groups were not observed. In the material series TPU-NC1 to TPU-NC8, the lack of bands for structural stretching - $\mathrm{OH}$ groups indicated the complete tethering of the organoclay -OH groups with polyurethane, while in the case of TPU-NC10, a certain amount of -OH groups stayed unreacted and produced the characteristic band at $3625 \mathrm{~cm}^{-1}$. The current results agree with those reported by Dimitry et al. ${ }^{24}$

The band positions of functional groups in pure TPU and TPU-NCs were indistinguishable, which confirmed the two groups of materials shared the same chemical structure, despite silicate layers being present in TPUs. Analysis by FTIR showed lack of an isocyanate group in the TPUNCs and in TPU (there was no absorption band at $2270 \mathrm{~cm}^{-1}$ ), while new bands were seen in two key vibrational regions: the $v_{\mathrm{N}-\mathrm{H}}$ stretching vibration $\left(3150-3500 \mathrm{~cm}^{-1}\right)$ and the $v_{\mathrm{C}=\mathrm{O}}$ stretching vibration in the amide I region $\left(1650-1780 \mathrm{~cm}^{-1}\right){ }^{35}$ The areas and exact localities of all peaks in the $\mathrm{CO}$ and $\mathrm{NH}$ regions were able to be determined by analysis of FTIR results (fitted by a Gaussian deconvolution technique). ${ }^{46}$

In the CO region, three absorbance peaks were obvious in both pure TPU and TPU-NCs: hydrogen-bonded carbonyl groups in the ordered (crystalline) hard domains at $1702 \mathrm{~cm}^{-1}$, free (non-bonded) carbonyl groups at $1733 \mathrm{~cm}^{-1}$, and hydrogen-bonded carbonyl groups in the disordered (amorphous) domains at $1714 \mathrm{~cm}^{-1}$. ${ }^{49}$ In the $-\mathrm{NH}$ stretching region, a clearly defined absorption band at $3320 \mathrm{~cm}^{-1}$ correlated to H-bonded -NH groups, while free -NH groups were not detected in the region from 3400 to $3500 \mathrm{~cm}^{-1}$ (the infrared wavelengths). ${ }^{50}$

The band correlating to H-bonded -NH groups of TPU-NC1 was of marginally greater intensity than those of pure TPU and other TPU-NCs, confirming that supplementary hydrogen bonds had been formed between the TPU matrix and the organoclay, probably due to good dispersion of organoclay nanoparticles.

To measure the influence of organoclay nanoparticles on the degree of phase separation in the TPU-NCs, the amount of hydrogen bonding in hard segments was studied. ${ }^{22,51,52}$ The formation of hydrogen bonds is revealed by studying areas of three bands determined by 
deconvolution of carbonyl regions. The degree of phase separation (DPS) in TPU-NCs is calculated by using Eq. (2): ${ }^{52}$

$$
D P S=\frac{A_{\text {bonded }, \text { tot }}}{A_{\text {tot }}}=\frac{A_{1702}+A_{1714}}{A_{1702}+A_{1714}+A_{1733}}
$$

There was no significant difference in the DPS of pure TPU (75\%) and the DPS of the TPUNCs with 1, 3 and 5 wt \% of organoclay loadings (74, 73 and 71\%, respectively), which could be due to silicate layers being uniformly dispersed in the TPU matrix. ${ }^{22}$ Furthermore, it is noticeable that organoclay loadings of 8 and $10 \mathrm{wt} \%$ decreased the phase separation (65 and $60 \%$ for TPUNC8 and TPU-NC10, respectively) as compared with pure TPU. The decreased values of DPS could be due to the disruption of phase separation in the synthesized TPU-NC8 and TPU-NC10 materials. Further, the DPS obtained for TPU/C30B-10 (68\%) was higher than that of TPUNC10.

3.1.2. SWAXS analysis. SAXS was used to obtain simultaneous information on organoclay dispersion as well as on phase morphology of the materials. Analyses at different $q$ regions differentiates between TPU morphology and contributions from the nanofillers, since Osman et al. state that " $q$ is inversely proportional to the length scales of both components". ${ }^{31}$

SWAXS measurements of the pure TPU, Cloisite 30B and TPU-NC1, TPU-NC3, TPU-NC5, TPU-NC8 and TPU-NC10 were performed in the region $q=(0.05-40) \mathrm{nm}^{-1}$. Figure 3 shows the SWAXS overview of scattering data of pure TPU, Cloisite 30B and selected TPU-NCs with different organoclay content. SWAXS profiles for all synthesized TPU-NCs are shown in Figure S1 (Supporting Information).

In the lowest $q$ region, SAXS dependencies coincided, showing that large scale properties did not depend on the amount of organoclay added to the materials.

In the highest $q$ region, the pattern is a superposition of that of the TPU and organoclay. An exception is a peak at $14.9 \mathrm{~nm}^{-1}$, corresponding to $0.42 \mathrm{~nm}$, which exists neither in pure TPU nor in Cloisite 30B. It is probably a result of some physical or chemical interaction of TPU and organoclay layers on the small scale. Its precise character is, however, hard to judge from one peak, so this is speculation on our part. 
The scattering curve of Cloisite $30 \mathrm{~B}$ exhibits a peak $\sim 3.2 \mathrm{~nm}^{-1}$. According to the literature, ${ }^{25}$ this peak is believed to stem from the distance of the platelets. Our results show that this peak is, in the case of TPU-NCs, shifted down to $q$ values which are lower. This can be due to intercalation, resulting in an increase of the platelets' distance. This shift can be seen more clearly for all TPU-NCs when the TPU scattering is subtracted, as is depicted in Figure S2 (Supporting Information). The result of this subtraction is shown purely for illustrative reasons.

To use the measured data maximally, a fit to a proper structural model should be attempted. Since our system was very complex, we studied the SAXS region more thoroughly, using mathematical modeling, and attempting explain the existence and behavior of various peaks revealed in this study using the sasfit ${ }^{53}$ program. Figure S3 (Supporting information) depicts an example of such a fit for TPU-NC8, including the model components.

The model is 2D Guinier, which reflects the layered structure and includes the effect for very low $q$. The broad peak of the TPU is fitted by a Lorentz function, as are the first and second order peaks caused by the presence of lamellar structures. Some important parameters from these fits are given in Table 1. Here, $\mathrm{q}_{1}$ and $\mathrm{a}_{1}$ are parameters for the first 'TPU' peak, while $\mathrm{q}_{2}$ and $\mathrm{q}_{3}$ are positions of peaks originating from the intercalated layers.

With increasing organoclay content, we observed the following:

- Although curves for pure TPU and TPU with $1 \mathrm{wt} \%$ of organoclay content differed slightly in the middle SAXS region, it was not possible to fit organoclay properties reliably in the latter dependency. We speculate that this could be due to too low concentration of organoclay or exfoliation, but this cannot be confirmed from our data.

- TPU peak intensity increased while the maximum shifted to lower $q$. This downwards shift could be interpreted as being due to hydrophilic clay layers interacting with polyurethane segments, so altering the morphology of the TPU. The TPU, then, would comprise fewer defined phases and interfaces, while its hard domains would be further apart, potentially because phase mixing occurred to a greater extent. ${ }^{54,55}$

- When the materials included organoclay nanoparticles, $q$ was low, and scattering intensities tended to increase. The organoclay nanoparticles are hydrophilic, so they interreact with polyurethane segments (in the current study, with hard segments), meaning the microphase separation process alters, and new nanostructures form in the TPU. ${ }^{54,55}$ 
- The first order of intercalation peak shifted very slightly toward higher $q$. Adding organoclay resulted in lower interdomain spacing, signifying that when Cloisite 30B was included, increased lamellar ordering occurred..$^{22,23}$

3.1.3. SEM analysis. The morphology of cryo-fractured surfaces of TPU-NCs was observed using SEM analysis. Typical microphotographs of TPU-NCs are presented in Figure 4. SEM images show that the fracture surfaces became rougher when the organoclay was incorporated in the materials, compared to the surface of pure TPU (TPU-NC0). The bright spots observed on the surface correspond to organoclay particles either dispersed (1 and $3 \mathrm{wt} \%)$ or aggregated (5, 8 and 10 wt $\%$ of clay) within the polyurethane matrix. ${ }^{56}$ The SEM analysis indicates that the structure of TPU-NCs with organoclay loadings higher than $3 \mathrm{wt} \%$ consisted mainly of agglomerated organoclay particles. TPU-NC10 even had parts with partly continuous organoclay agglomerates.

3.1.4. AFM analysis. AFM was used to study and measure differences in surface relief and surface morphologies of the TPU-NCs. The height and phase of AFM images of $2 \mu \mathrm{m} \times 2 \mu \mathrm{m}$ surfaces on the materials were selected and are shown in Figure 5. The images of pure TPU and the TPU-NCs showed their surfaces were dissimilar: the topography of TPU displayed a smooth surface, while the TPU-NCs had rough surfaces. Furthermore, the topography of TPU-NCs did not change significantly with different organoclay content. Roughness values for all materials are summarized in Table 2. Clearly, roughness largely depended on the presence or absence of organoclay; TPU-NCs had higher roughness in comparison with pure TPU: all $R_{\mathrm{a}}$ values of nanocomposites were of the order $10^{1} \mathrm{~nm}$ (without any systematic trend of $R_{\mathrm{a}}$ vs. clay content) while the $R_{\mathrm{a}}$ value of the pure TPU (TPU-NC0) is of the $10^{\circ}$ order.

Phase images enabled qualitative examination of the heterogeneity of surface reliefs. Figure 5 shows the pure TPU had a homogeneous character, while all synthesized TPU-NCs exhibited heterogeneity of their surface reliefs, caused by the presence of the organoclay nanoparticles. The bright areas depict the TPU matrix, while the dark regions are organoclay nanoparticles. ${ }^{23}$ The phase reliefs of nanocomposites containing 1 to $8 \mathrm{wt} \%$ organoclay were all very similar. This indicates that increasing organoclay concentration has almost no influence on the arrangement of organoclay particles on the nanometer scale in the TPU-NCs. However, in TPU-NC1, fewer agglomerate polymer or organoclay structures were visible, compared to those of TPU-NC3 to 
TPU-NC8. Finally, TPU-NC10 also contains (infrequent) continuous organoclay and polymer regions, besides the visible agglomerates. The internal arrangement in TPU-NC10 resulted in the much lower $R_{\mathrm{a}}$ value (see Table 2), but it was probably also responsible for the notably different thermal properties of TPU-NC10 (e.g. $T_{10 \%}$ shift to lower temperature compared to the other nanocomposites and TPU matrix, as detected by TGA (see part 3.2)).

3.2. Thermal Properties. DSC and TGA were used to determine the effects of incorporating organoclay on the thermal properties of the TPUs. DSC thermograms of the TPU-NCs and TPU are shown in Figure 6 . Table 3 summarizes glass transition temperatures $\left(T_{\mathrm{gHS}}\right)$, melting temperatures $\left(T_{\mathrm{mHS}}\right)$, enthalpies of melting $\left(\Delta H_{\mathrm{mHS}}\right)$, crystallization temperatures $\left(T_{\mathrm{cHS}}\right)$, crystallization enthalpies $\left(\Delta H_{\mathrm{cHS}}\right)$ and degrees of crystallinity $\left(X_{\mathrm{c}}^{\mathrm{HS}}\right)$ of pure TPU, TPU-NCs and TPU/C30B-10 measured by DSC. The presence of organoclay particles affected the materials' thermal properties. The hard phase of pure TPU shows melting and crystallization temperatures at 157 and $84{ }^{\circ} \mathrm{C}$, respectively, whereas for TPU-NCs, $T_{\mathrm{mHS}}$ and $T_{\mathrm{cHS}}$ were registered as much broader peaks and were shifted toward higher temperatures, which might indicate the positive influence of additional hydrogen bonding on the initiation of physical crosslink disruption. ${ }^{57}$ An increase in $T_{\mathrm{mHS}}$ occurred when organoclay content increased from 3 to $5 \mathrm{wt} \%$, but not with a further increase in organoclay amounts (up to $10 \mathrm{wt} \%$ ) (Table 3). The $T_{\mathrm{m}}$ of TPU/C30B-10 was significantly lower than of TPU-NC10, but it was closer to that of pure TPU, which confirms organoclay-polymer reactions did indeed occur in TPU-NC series. The glass transition temperatures of the hard segment in TPU-NCs with organoclay loadings $\leq 5 \mathrm{wt} \%$ occurred at lower temperatures than that of pure TPU (Table 3). The slight increase of $T_{\mathrm{g}}$ value in TPU-NC10 as compared to TPU/C30B-10 was due to organoclay particles becoming bound to polymer chains, a feature not seen in TPU/C30B-10. ${ }^{19}$

An interesting fact is that hard segment crystallization was hampered in TPU-NCs containing up to $5 \mathrm{wt} \%$ organoclay, as can be observed by the slightly lower $\Delta H_{\mathrm{cHS}}$ and $\Delta H_{\mathrm{mHS}}$ as well as $X_{\mathrm{c}}^{\mathrm{HS}}$ values (Table 3 ). The degree of crystallinity of the hard segment $\left(X_{\mathrm{c}}^{\mathrm{HS}}\right)$ in the materials was calculated using the enthalpies of melting of samples, the mass $\%$ of hard segment, ${ }^{58}$ and with the enthalpy of melting of $100 \%$ crystalline MDI-BD homopolymer $=91.2 \mathrm{~J} / \mathrm{g},{ }^{59}$ as previously described. ${ }^{32-35}$ Pure TPU and TPU/C30B-10 had a degree of crystallinity of $19 \%$ and $18 \%$, respectively. The degree of crystallinity of the nanocomposites ranged from 14 to $18 \%$ (Table 3 ). 
The $X_{\mathrm{c}}^{\mathrm{HS}}$ value decreased as organoclay levels increased up to $5 \mathrm{wt} \%$, after which $X_{\mathrm{c}}^{\mathrm{HS}}$ values increased with further increases of organoclay content. The decrease in enthalpies of TPU-NCs could be brought about by organoclay particles interacting with hard segments, which makes the packing of these domains difficult. ${ }^{60}$ Thus, as a consequence of the presence of organoclay particles in the nanocomposite structure, the crystallization rate of the polyurethane hybrid decreases. Strankowski et al. ${ }^{60}$ found that melting temperatures for TPU-NCs containing 1 wt $\%$ of Cloisite $10 \mathrm{~A}$ and Cloisite 20A increased in comparison with pure TPU. However, the transition enthalpy for nanocomposites containing 1wt \% Cloisite 10A was higher, while for the nanocomposites containing $1 \mathrm{wt} \%$ Cloisite 20A, it was lower, compared to pure TPU. They found that nanofiller Cloisite 10A, most probably having a significant chemical affinity towards polyurethane chains, can increase the density of the nucleation process and, as a consequence, a higher value of crystallization enthalpy for TPU-NCs containing Cloisite 10A is observed in comparison with TPU-NCs containing Cloisite $20 \mathrm{~A} .{ }^{60}$ On the other hand, Eceiza et al. ${ }^{25}$ believed that the decreased crystallinity of hard segment in TPU nanocomposites based on poly(caprolactone)- $b$-poly(tetradydrofuran)- $b$-poly(caprolactone) diol and Cloisite 30B, as compared to that of pure TPU, could be due to the materials being more viscous when polyurethane chains interact with organoclay; the authors proposed that viscosity deterred HS crystallization. In our study, slightly greater $\Delta H_{\mathrm{mHS}}$ and $X_{\mathrm{c}}^{\mathrm{HS}}$ values were observed only for TPUNC8 and TPU-NC10 in our series of synthesized TPU-NCs. This could have been because of organoclay agglomerating, meaning the clay would interfere less with the crystallization of the hard segments, and it offered less interfacial surface to interact with the TPU.

TGA was utilized to study the thermal degradation of pure TPU and TPU-NCs. Figure 7 shows TGA a) and DTG b) thermograms of Cloisite 30B, pure TPU, TPU/C30B-10 and TPUNCs. Initial degradation temperatures $\left(T_{10 \%}\right)$, maximum rate degradation temperatures $\left(T_{\max }\right)$, and residual weights of the materials are presented in Table 3. The initial degradation temperature, defined as the temperature of $10 \%$ weight loss, was used to indicate the materials' thermal stability. The results obtained showed that the $T_{10 \%}$ of TPU-NCs synthesized with organoclay loadings lower than $5 \mathrm{wt} \%$ were higher than the $T_{10 \%}$ of pure TPU. The $T_{10 \%}$ value of TPU/C30B-10 was lower than that of pure TPU and other synthesized TPU-NCs. TPU-NC1 was the most thermally stable material synthesized. The $T_{10 \%}$ of the materials decreased with increasing organoclay content for TPU-NC8 and TPU-NC10 (Table 3). This was probably as a 
result of the reduced interfacial surfaces between organoclay and the TPU matrices, but more agglomerates were also observed with continuous organoclay in the material with the highest organoclay content, which was confirmed by AFM (above). The results obtained showed that materials with low organoclay loadings had the highest $T_{10 \%}$ and $T_{\max }$ values (Table 3 ). According to Leszczyńska et al. ${ }^{61}$, improved thermal stability of polymer/clay nanocomposites is likely because the clay layers block the movement of any gases, including, of course, degraded products which happen to be volatile. Additionally, they observed that clay platelets also obstruct heat and polymer movement. ${ }^{61}$

The temperatures at which weight loss was maximized in the TPU-NCs $\left(T_{\max }\right.$, Table 3$)$ were higher relative to the curve for the pure TPU matrix, in a trend that followed increasing amounts of organoclay in the TPU-NCs. Thus, the TPU-NCs were more thermally stable than TPU, which was expected from some previous work which noted improved thermal stability when the polyurethane matrix contained organoclay. ${ }^{25}$ From Figure 7, it is clear that the thermal decomposition of TPU and TPU-NCs consisted of three decomposition steps: the first step involved decomposition of hard segments and is connected to the breaking of urethane bonds, the second step could be assigned to the soft PDMS components decomposing, while third step is related to the aromatic compounds decomposing. The temperature of the first decomposition step (assigned to the scission of urethane links), increased with up to $5 \mathrm{wt} \%$ of organoclay (from 313 ${ }^{\circ} \mathrm{C}$ for pure TPU to $322-352{ }^{\circ} \mathrm{C}$ for TPU-NC1 to TPU-NC5) and then decreased with further organoclay content increases $\left(332{ }^{\circ} \mathrm{C}\right.$ for TPU-NC8 and TPU-NC10). On the other hand, the second decomposition peak temperature (connected to the decomposition of the soft segment) increased with the increase of organoclay content (from $338{ }^{\circ} \mathrm{C}$ for pure TPU to $437-464{ }^{\circ} \mathrm{C}$ for TPU-NCs). These results show that organoclay addition up to $5 \mathrm{wt} \%$ positively affected thermal stability $\left(T_{10 \%}\right)$ and the initiation of the breaking of urethane bonds (in the hard segment), but further increasing the organoclay content had more negative effects on thermal stability and thermal decomposition of the hard segment. Also, the results show the presence of organoclay positively affected thermal decomposition of the soft segment. In addition, according to TGA and DTG curves, organoclay C30B decomposed in three steps in the interval $200-650{ }^{\circ} \mathrm{C}$, and as related to the decomposition of organoclay modifier. ${ }^{62,63}$ Organoclay modifier completely decomposed at $700{ }^{\circ} \mathrm{C}$ and only thermally stable inorganic clay $(70 \mathrm{wt} \%)$ remained. 
The results indicate that clay-polymer reactions affected the thermal degradation behavior of TPU-NCs. The thermal stability and the first and second decomposition peak temperatures of TPU-NC10 were higher than those for TPU/C30B-10 (Table 3).

The residue of TPU-NC0 was 2.7 wt $\%$ at $650{ }^{\circ} \mathrm{C}$, while higher residual weights were found for TPU-NCs, due to the presence of organoclay (Table 3). The residual weight increased with the level of organoclay loading.

3.3. Dynamic Mechanical Thermal Properties. DMTA analysis was used to investigate the phase transitions in the pure TPU and TPU-NCs. The dynamic mechanical properties of the differing TPU-NCs were also studied. The storage moduli $\left(G^{\prime}\right)$ and mechanical loss factors (tan $\delta$ ) for the materials under changing temperatures are displayed (Figure 8), while Table 4 shows DMTA results. The $G^{\prime}$ vs. temperature and $\tan \delta$ vs. temperature graphs in Figure 8 show glass transitions of between -104 to $-110{ }^{\circ} \mathrm{C}$ for TPU-NCs, which were likely associated with segmental motion in the PDMS ( $\left.T_{\mathrm{gPDMS}}\right)$. Addition of various organoclay contents did not alter the peak positions compared to that of pure TPU, except for those of TPU-NC8 (Table 4). Similar results were obtained for TPU/layered silicate nanocomposites based on polycarbonate with 1 or 2 wt \% of organoclay and for TPU nanocomposites with 1 wt \% of silica nanoparticles, which were reported by Špírková et al. ${ }^{13,64}$ Our current results showed no change of $T_{\text {gPDMS }}$ between the pure TPU matrix and the TPU-NCs, suggesting the presence of organoclay nanoparticles did not greatly affect the flexibility of EO-PDMS soft segments and, therefore, organoclay nanoparticles interact preferably with hard segments (except in TPU-NC8). ${ }^{64}$

The second process $\left(T_{\alpha 2}\right)$, observed at between 2 to $4{ }^{\circ} \mathrm{C}$ for the TPU-NCs (Table 4 ), is possibly due to segmental relaxation "of a mixed soft phase consisting of PDMS end group segments and some dissolved hard segments", as stated by Choi et al. ${ }^{65}$ The reduced $\alpha 2$ relaxation strength for TPU-NCs in comparison with the pure TPU matrix was due to the minimal proportion of hard segments in the mixed phases because of the presence of organoclay nanoparticles. The $T_{\alpha 2}$ of the TPU-NCs was somewhat increased when organoclay was present as compared with pure TPU. Phase mixing likely occurred between the hard and soft segments, as the organoclay made the different segment types more compatible, resulting in increased $T_{\alpha 2}$ of the soft segment, which is accordance with Osman et al. ${ }^{30}$ Hernandez et al. ${ }^{66}$ also endorsed this idea when they found $T_{\alpha 2}$ was affected when single MDI and short MDI-BD sequences were 
introduced in the soft phase. In our study, the $G^{\prime}$ vs. temperature and $\tan \delta$ vs. temperature dependencies showed glass transition temperatures of between 86 to $93{ }^{\circ} \mathrm{C}$ for TPU-NCs, and which were affiliated with the hard segment $\left(T_{\mathrm{gHS}}\right.$; Table 4$)$. For TPU-NCs, increases in organoclay levels meant $\tan \delta$ temperatures were higher, indicating that organoclay nanoparticles interacted with hard segments. DPS was nearly unaffected by the addition of organoclay, but in contrast, rheological properties like shear modulus $G^{\prime}$ and melting temperature and relaxation peak in $\tan \delta$ were affected (Table 4). Since there must be some origin of such behavior, we would emphasize that it is likely a result of organoclay interaction with hard segments. We cannot claim that organoclay arranges in such a way that there are no platelets in the soft segment or interphase. However, although the organoclay is homogenously dispersed, it nonetheless interacts preferably with hard segment domains. These interactions are realized mainly via Hbonding of urethane groups with organoclay oxygen atoms found on the edges of filler nanosheets, but also partially through van deer Waals and dipol-dipol interactions of highly polar carbonyl groups in urethane groups with quaternary amine salts.

In addition, TPU-NCs based on organoclay contents of $\leq 5 \mathrm{wt} \%$ had storage modulus increases (see above) at temperatures higher than $T_{\mathrm{gPDMS}}$, compared to pure TPU. These storage modulus increases probably occurred because organic/inorganic interface boundaries in the materials improved as the inorganic matter loadings increased. ${ }^{25,67}$ At organoclay loadings of $8 \mathrm{wt}$ $\%$, the organoclay reinforcing effect became weaker, as seen from the decreased $G^{\prime}$ (compared to TPU-NC5), probably due to lower organoclay-polymer surface interaction and the presence of organoclay agglomerates. Increased storage modulus is a result of an increased number of physical crosslinks. This is the case when the filler concentration is lower, and an effective reinforcement occurs. Above a certain concentration, aggregates form and physical crosslinks are disrupted, and the system seems to be oversaturated with filler. At high filler loadings, there are simply not enough urethane groups to efficiently interact and reinforce the structure.

The melting temperatures $\left(T_{\mathrm{mHS}}\right)$ of the crystalline parts of MDI-BD units of TPU-NCs occurred in the range between 142 and $202{ }^{\circ} \mathrm{C}$ (Table 4). The melting temperatures for TPU-NCs shifted toward higher values as compared to pure TPU, and a significant increase of $T_{\mathrm{mHS}}$ was observed for TPU-NC8, probably due to the aggregation effect of organoclay. 
3.4. Water Contact Angle and Surface Free Energy. The water contact angle values are shown in Figure 9. The water contact angle for pure TPU was $111.5 \pm 0.2^{\circ}$, which indicated the hydrophobic nature of this material. On the other hand, the water contact angles for TPU-NCs were inversely correlated with organoclay levels (Figure 9), and were lower than that of pure TPU. The TPU-NCs with organoclay content from 1 to $8 \mathrm{wt} \%$ were hydrophobic, while TPUNC10 was hydrophilic, as was TPU/C30B-10.

Decrease of water contact angle with increase of organoclay content probably occurred because, although the organoclay -OH groups react with -NCO prepolymer groups, some free $\mathrm{OH}$ groups exist and are ready for hydrogen bonding. ${ }^{68,69}$ As organoclay particles can also be found near the composite surface, hydrogen bonding can occur between free -OH groups and water. Decreasing water contact angles in our material series from TPU-NC1 to TPU-NC10 indicates that the method used for determining water contact angle was more sensitive in detecting free -OH groups on the materials' surfaces than FTIR. In the case of TPU-NC10, FTIR spectra suggested the existence of free $-\mathrm{OH}$ groups, and that point, in terms of composite composition, can be set as a sensitivity point for free -OH group detection by FTIR using conventional spectra acquisition.

Figure 10 shows surface energies of the synthesized materials. TPU-NCs exhibited higher surface free energy compared to the pure TPU (TPU-NC0). Furthermore, increases in both the dispersive and polar components of surface energy were seen (surface energy components were smaller), as organoclay content increased (Figure 10a). The electron-acceptor interactions slightly decreased in the TPU-NC materials, while contributions from electron-donor interactions slightly increased for the TPU-NCs with increasing organoclay content (Figure 10b). Therefore, surface free energy of the TPU-NCs increased with increasing amounts of organoclay in our materials, suggesting that the presence of organoclay $\mathrm{C} 30 \mathrm{~B}$ made the surface less hydrophobic. These results are in agreement with results reported by Osman et al. ${ }^{30}$ and Muppalla et al. ${ }^{69}$

The surface free energy of TPU/C30B-10 was higher and water contact angle of TPU/C30B10 was lower than those of TPU-NC10, due to differences in hydrogen bonding between organoclay and TPU in both samples.

Overall, the surface of the TPU-NCs became less hydrophobic, the surface roughness mostly increased, while thermal stability and thermomechanical properties improved with increasing 
organoclay loadings (up to $\leq 5 \mathrm{wt} \%$ ), suggesting great promise for the possible use of TPU-NC films with low organoclay content in potential biomedical applications.

\section{Conclusion}

A novel series of PDMS-based TPU nanocomposites with $20 \mathrm{wt} \%$ of hard segment was synthesized using in situ polymerization. The novel TPU-NCs contained from 1 to $10 \mathrm{wt} \%$ of Cloisite $30 \mathrm{~B}$ as a nanoclay.

On the basis of FTIR spectra obtained for the TPU-NCs, conclusions can be made about the organoclay dispersion achieved. The most uniform dispersion of organoclay was obtained in TPU-NC1, as attested to by the relatively intense H-bonded -NH band compared with the same band in our material series TPU-NC3 to TPU-NC10. This conclusion was also confirmed by SEM and AFM analyses. Lack of a $3626 \mathrm{~cm}^{-1}$ band in FTIR spectra for the TPU-NC1 to TPUNP8 material series suggests the existence of tethering reactions of polyurethane and organoclay and hydrogen bonding between free $-\mathrm{OH}$ organoclay group and polyurethane chains. This conclusion was confirmed by water contact angle measurements. These measurements also lead to the conclusion that free -OH groups exist on the surfaces of the TPU-NCs, and which increased the hydrophilicity from TPU-NC1 to TPU-NC10. Also, this indicates that water contact measurement is a more sensitive method for monitoring the existence of free - $\mathrm{OH}$ groups on the surface of organoclay composites than FTIR. The surface of freeze-fractured pure TPU was smoother than the surface of all the TPU-NCs. Moreover, in AFM images, the relatively smooth and homogeneous character of pure TPU, and the distinctly heterogeneous and rough surfaces of TPU-NCs were detected. SEM images enabled visualization of individual organoclay particles on cross-sectional surfaces of materials with lower organoclay loadings ( 1 or $3 \mathrm{wt} \%$ ), or organoclay agglomerates on TPUs with higher amounts of organoclay ( $\geq 5 \mathrm{wt} \%$ ). SWAXS confirmed that intercalated nanocomposite morphology was obtained.

Based on TGA and DMTA, organoclay loadings $(\leq 5 \mathrm{wt} \%)$ increased both thermal stability and storage modulus due to large interfacial surfaces between polymer and organoclay. DSC and DMTA revealed four thermal transitions, and these generally depended on the organoclay content. The first thermal transition $\left(-102\right.$ to $\left.-110{ }^{\circ} \mathrm{C}\right)$ corresponded to the glass transition temperature of soft PDMS segments. The second transition occurred at temperatures from 2 to 4 
${ }^{\circ} \mathrm{C}$. The third transition, located from 86 to $93{ }^{\circ} \mathrm{C}$, corresponded to the glass transition temperature of hard segments. The fourth thermal transition (142 to $\left.202{ }^{\circ} \mathrm{C}\right)$ was due to crystalline, highly organized hard segments being disrupted. Organoclay nanoparticles interact preferably with hard segment, as detected by FTIR, DSC and DMTA. The degree of crystallinity, determined by DSC, first decreased with up to $5 \mathrm{wt} \%$ of organoclay and then increased with further increase of organoclay content. This was due to the agglomeration effect of organoclay, because the nanoclay interferes less with the crystallization of the hard segments and it offers less interfacial surface to interact with the TPU.

In conclusion, taking into account FTIR, SEM, AFM and water contact angle measurements, the new nanocomposite material TPU-NC1 had the best functional properties in regards to organoclay content. Considering that such novel, prepared TPU-NC films with low organoclay content could be exceptionally suited to biomedical applications, biocompatibility assessment and tensile testing of these nanocomposites are suitable topics for further study.

\begin{abstract}
Associated content
Supporting Information

SWAXS profiles of Cloisite 30B and TPU-NCs and SAXS data processed by the mathematical treatment in order to increase the resolution of small scattering peaks in SAXS profiles for TPU-NCs (for example TPU-NC8). These materials are available free of charge via the Internet at http://pubs.acs.org.
\end{abstract}

Acknowledgment. This work was financially supported by the Ministry of Education, Science and Technological Development of the Republic of Serbia (Project No. 172062) and by the Czech Science Foundation (Grant Agency of the Czech Republic, Project No. 13-06700S). 


\section{References}

(1) Chu, B.; Gao, T.; Li, Y. J.; Wang, J.; Desper, C. R. Byrne, C. A. Microphase Separation Kinetics in Segmented Polyurethanes - Effects of Soft Segment Length and Structure, Macromolecules 1992, 25, 5724.

(2) Elwell, M. J.; Ryan, A. J.; Grunbauer, H. J. M.; Van Lieshout, H. C. In-situ Studies of Structure Development During the Reactive Processing of Model Flexible Polyurethane Foam Systems Using FT-IR Spectroscopy, Synchrotron SAXS, and Rheology, Macromolecules 1996, 29, 2960.

(3) Ryan, A. J.; Willkomm, W. R.; Bergstrom, T. B.; Macosko, C. W.; Koberstein, J. T.; Yu, C. C.; Russell, T. P. Dynamics of (Micro)phase Separation During Fast, Bulk Copolymerization Some Synchrotron SAXS Experiments, Macromolecules 1991, 24, 2883.

(4) Martin, D. J.; Osman, A. F.; Andriani, Y.; Edwards, G. A. Thermoplastic Polyurethane (TPU)-based Polymer Nanocomposites. In: Gao F., editor. Advances in Polymer Nanocomposites: Woodhead Publishing Limited; 2012. p 321-350.

(5) Yilgör, E.; Yilgör, I. Silicone Containing Copolymers: Synthesis, Properties and Applications, Prog. Polym. Sci. 2014, 39, 1165.

(6) Yilgör, I.; McGrath, J. E. Polysiloxane Containing Copolymers: A Survey of Recent Developments. Adv. Polym. Sci. 1988, 86, 1.

(7) Vermette, R.; Griesser, H. J.; Laroche, G.; Guidoin, R. Biomedical Applications of Polyurethanes. Texas: Landes Bioscience, 2001.

(8) Finnigan, B.; Martin, D.; Halley, P.; Truss R.; Campbell, K. Morphology and Properties of Thermoplastic Polyurethane Composites Incorporating Hydrophobic Layered Silicates. J. Appl. Polym. Sci. 2005, 97, 300.

(9) Pashaei, S.; Siddaramaiah; Syed, A. A. Thermal Degradation Kinetics of Polyurethane/Organically Modified Montmorillonite Clay Nanocomposites by TGA. $J$. Macromol. Sci., Part A 2010, 47, 777.

(10) Malay, O.; Oguz, O.; Kosak, C.; Yilgor, E.; Yilgor, I.; Menceloglu, Y. Z. Polyurethaneureasilica Nanocomposites: Preparation and Investigation of the Structure-Property Behavior. Polymer 2013, 54, 5310.

(11) Taheri, S.; Mohamad Sadeghi, G. M. Microstructure-Property Relationships of Organomontmorillonite/Polyurethane Nanocomposites: Influence of Hard Segment Content. Appl. Clay Sci. 2015, 114, 430.

(12) Andriani, Y.; Morrow, I. C.; Taran, E.; Edwards, G. A.; Schiller, T. L.; Osman, A. F.; Martin, D. J. In Vitro Biostability of Poly(dimethyl siloxane/hexamethylene oxide)-based Polyurethane/Layered Silicate Nanocomposites. Acta Biomater. 2013, 9, 8308.

(13) Poręba, R.; Špírková, M.; Brožová, L.; Lazić, N.; Pavličević, J.; Strachota, A. Aliphatic Polycarbonate-based Polyurethane Nanostructured Materials. The Influence of the Composition on Thermal Stability and Degradation J. Appl. Polym. Sci. 2013, 127, 329.

(14) Chang, J.-H.; An, Y. U. Nanocomposites of Polyurethane with Various Organoclays: Thermomechanical Properties, Morphology, and Gas Permeability. J. Polym. Sci. Part B: Polym. Phys. 2002, 40, 670.

(15) Xiong, J.; Zheng, Z.; Jiang, H.; Ye, S.; Wang, X. Reinforcement of Polyurethane Composites with an Organically Modified Montmorillonite. Comp. Part A: Appl. Sci. Manuf. 2007, 38, 132. 
(16) Chen-Yang, Y. W.; Lee, Y. K.; Chen, Y. T.; Wu, J. C. High Improvement in the Properties of Exfoliated PU/Clay Nanocomposites by the Alternative Swelling process. Polymer 2007, 48, 2969.

(17) Wang, H. H.; Chen, K. V. A Novel Synthesis of Reactive Nano-Clay Polyurethane and its Physical and Dyeing Properties. J. Appl. Polym. Sci. 2007, 105, 1581.

(18) Tien, Y. I.; Wei, K. H. The Effect of Nano-Sized Silicate Layers from Montmorillonite on Glass Transition, Dynamic Mechanical, and Thermal Degradation Properties of Segmented Polyurethane. J. Appl. Polym. Sci. 2002, 86, 1741.

(19) Pattanayak, A.; Jana, S. C. Synthesis of Thermoplastic Polyurethane Nanocomposites of Reactive Nanoclay by Bulk Polymerization Methods. Polymer 2005, 46, 3275.

(20) Špírková, M.; Pavlićević, J.; Strachota, A.; Poreba R.; Bera, O.; Kapralkova, L.; Baldrian, J.; Šlouf, M.; Lazić, N.; Budinski-Simendić, J. Novel Polycarbonate-based Polyurethane Elastomers: Composition-Property Relationship. Eur. Polym. J. 2011, 47, 959.

(21) Pavlićević, J.; Špírková, M.; Strachota, A.; Meszaros Szecsenyi, K.; Lazić, N.; BudinskiSimendić, J. The Influence of Montmorillonite and Bentonite Addition on Thermal Properties of Polyurethanes based on Aliphatic Polycarbonate Diols. Thermochim. Acta 2010, 509, 73.

(22) Pavlićević, J.; Špirkova, M.; Jovičić, M.; Bera, O.; Poreba, R.; Budinski-Simendić, J. The Structure and Thermal Properties of Novel Polyurethane/Organoclay Nanocomposites Obtained by Pre-polymerization, Composites: Part B 2013, 45, 232.

(23) Špírková, M.; Poreba, R.; Pavlićević, J.; Kobera, L.; Baldrian, J.; Pekárek, M. Aliphatic Polycarbonate-based Polyurethane Elastomers and Nanocomposites. I. The Influence of HardSegment Content and Macrodiol-Constitution on Bottom-Up Self-Assembly, J. Appl. Polym. Sci. 2012, 126, 1016.

(24) Dimitry, O. I. H.; Abdeen, Z. I.; Ismail, E. A.; Saad, A. L. G. Preparation and Properties of Elastomeric Polyurethane/Organically Modified Montmorillonite Nanocomposites, J. Polym. Res. 2010, 17, 801.

(25) Rueda, L.; Garcia, I.; Palomares, T.; Alonso-Varona, A.; Mondragon, I.; Corcuera, M.; Eceiza, A. The Role of Reactive Silicates on the Structure/Property Relationships and Cell Response Evaluation in Polyurethane Nanocomposites. J. Biomed. Mater. Res. Part A 2011, 97, 480.

(26) Jeong, E. H.; Yang, J.; Hong, J. H.; Kim, T. G.; Kim, J. H.; Youk, J. H. Effective Preparation of Montmorillonite/Polyurethane Nanocomposites by Introducing Cationic Groups into the Polyurethane Main Chain. Eur. Polym. J. 2007, 43, 2286.

(27) Meng, X.; Du, X.; Wang, Z.; Bi, W.; Tang, T. The Investigation of Exfoliation Process of Organic Modified Montmorillonite in Thermoplastic Polyurethane with Different Molecular Weights. Compos. Sci. Technol. 2008, 68, 1815.

(28) Meng, X.; Wang, Z.; Yu, H.; Du, X.; Li, S.; Wang, Y.; Jiang, Z.; Wang, Q.; Tang, T. A. Strategy of Fabricating Exfoliated Thermoplastic Polyurethane/Clay Nanocomposites via Introducing Maleated Polypropylene. Polymer, 2009, 50, 3997.

(29) Xu, R. J.; Manias, E.; Snyder, A. J.; and Runt, J. Low Permeability Biomedical Polyurethane Nanocomposites. J. Biome. Mater. Res. Part A, 2003, 64A, 114.

(30) Osman, A. F.; Edwards, G. A.; Schiller, T. L.; Andriani, Y.; Jack, K. S.; Morrow, I. C.; Halley, P. J.; Martin, D. J. Structure-Property Relationships in Biomedical Thermoplastic Polyurethane Nanocomposites, Macromolecules 2012, 45, 198. 
(31) Osman, A. F.; Andriani, Y.; Edwards, G. A.; Schiller, T. L.; Jack, K. S.; Morrow, I. C.; Halley, P. J., Martin, D. J. Engineered Nanofillers: Impact on the Morphology and Properties of Biomedical Thermoplastic Polyurethane Nanocomposites, RSC Advances 2012, 2, 9151.

(32) Pergal, M. V.; Antic, V. V.; Tovilovic, G.; Nestorov, J.; Vasiljevic-Radovic, D.; Djonlagic, J. In Vitro Biocompatibility Evaluation of Novel Urethane-Siloxane Co-Polymers based on Poly(€-Caprolactone)-block-Poly(Dimethylsiloxane)-block-Poly( $\epsilon$-Caprolactone). J. Biomater. Sci. Polym. Ed. 2012, 23, 1629.

(33) Pergal, M. V.; Nestorov, J.; Tovilovic, G.; Ostojic, S.; Godevac, D.; Vasiljevic-Radovic, D.; Djonlagic, J. Structure and Properties of Thermoplastic Polyurethanes based on Poly(dimethylsiloxane): Assessment of Biocompatibility. J. Biomed. Mater. Res. Part A 2014, $102,3951$.

(34) Pergal, M. V.; Stefanovic, I. S.; Gođevac, D.; Antic, V. V.; Milacic, V.; Ostojic, S.; Rogan, J.; Djonlagic, J. Structural, Thermal and Surface Characterization of Thermoplastic Polyurethanes based on Poly(dimethylsiloxane). J. Serb. Chem. Soc. 2014, 79, 843.

(35) Stefanovic, I. S.; Djonlagic, J.; Tovilovic, G.; Nestorov, J.; Antic, V. V.; Ostojic, S.; Pergal, M. V. Poly(urethane-dimethylsiloxane) Copolymers Displaying a Range of Soft Segment Contents, Noncytotoxic Chemistry, and Nonadherent Properties Toward Endothelial Cells. J. Biomed. Mater. Res. Part A 2015, 103, 1459.

(36) Stefanović, I. S.; Špírková, M.; Poręba, R.; Steinhart, M.; Ostojić, S.; Tešević, V.; Pergal, M. V. Study of the Properties of Urethane-Siloxane Copolymers based on Poly(propylene oxide)- $b$ Poly(dimethylsiloxane)-b-Poly(propylene oxide) Soft Segments. Ind. Eng. Chem. Res. 2016, 55, 3960.

(37) Pergal, M. V.; Džunuzović, J. V.; Poręba, R.; Steinhart, M.; Pergal, M.; Vodnik, V.; Špírková, M. Structure-Property Correlation Study of Novel Poly(urethane-ester-siloxane) Networks. Ind. Eng. Chem. Res. 2013, 52, 6164.

(38) Špírková, M.; Machová, L.; Kobera, L.; Brus, J.; Poręba, R.; Serkis, M.; Zhigunov, A. Multiscale Approach to the Morphology, Structure, and Segmental Dynamics of Complex Degradable Aliphatic Polyurethanes. J. Appl. Polym. Sci. 2015, 132, 41590.

(39)Tomić, M.; Dunjić, B.; Likić, V.; Bajat, J.; Rogan, J.; Djonlagić, J. The Use of Nanoclay in Preparation of Epoxy Anticorrosive Coatings. Prog. Org. Coat. 2014, 77, 518.

(40) Król, P.; Pielichowska, K.; Špírková, M. Composites Prepared from the Waterborne Polyurethane Cationomers-Modified Graphene. Part I. Synthesis, Structure, and Physicochemical Properties. Colloid Polym. Sci. 2015, 293, 421.

(41) Van Oss, C. J.; Good, R. J.; Chaudhury, M. K. Additive and Nonadditive Surface Tension Components and the Interpretation of Contact Angles. Langmuir 1988, 4, 884.

(42) Fu, H.; Yan, C.; Zhou, W.; Huang, H. Preparation and Characterization of a Novel Organic Montmorillonite/Fluorinated Waterborne Polyurethane Nanocomposites: Effect of OMMT and HFBMA. Compos. Sci. Technol. 2013, 85, 65. 
(43) Pergal, M.; Nestorov, J.; Tovilović-Kovačević, G.; Jovančić, P.; Pezo, L.; VasiljevićRadović, D.; Djonlagić, J. Surface Characterization, Hemo- and Cytocompatibility of Segmented Poly(dimethylsiloxane)-based Polyurethanes. Hem. Ind. 2014, 68, 731.

(44) Wang, J.; Wang, L. The Lower Surface Free Energy Achievements from Ladder Polysilsesquioxanes with Fluorinated Side Chains. J. Fluorine Chem. 2006, 127, 287.

(45) Khayet, M.; Villaluenga, J. P. G.; Godino, M. P. Mengual, J. I.; Seoane, B.; Khulbe, K. C.; Matsuura, T. Preparation and Application of Dense Poly(phenylene oxide) Membranes in Pervaporation. J. Colloid Interface Sci. 2004, 278, 410.

(46) Pergal, M. V.; Džunuzović, J. V.; Poręba, R.; Ostojić, S.; Radulović, A.; Špírková, M. Microstructure and Properties of Poly(urethane-siloxane)s based on Hyperbranched Polyester of the Fourth Pseudo Generation. Prog. Org. Coat. 2013, 76, 743.

(47) Hwang, H. D.; Kim, H. J. Enhanced Thermal and Surface Properties of Waterborne UVCurable Polycarbonate-Based Polyurethane (Meth)acrylate Dispersion by Incorporation of Polydimethylsiloxane. React. Funct. Polym. 2011, 71, 655.

(48) Vince, J.; Orel, B.; Vilčnik, A.; Fir, M.; Šurca, V. A.; Jovanovski, V.; Simončić, B. Structural and Water-Repellent Properties of a Urea/Poly(dimethylsiloxane) Sol-Gel Hybrid and Its Bonding to Cotton Fabric. Langmuir 2006, 22, 6489.

(49) Pergal, M. V.; Antić, V..; Govedarica, M.; Gođevac, D.; Ostojic, J.; Djonlagić. Synthesis and Characterization of Novel Urethane-Siloxane Copolymers with a High Content of PCL-PDMSPCL Segments. J. Appl. Polym. Sci. 2011, 122, 2715.

(50) Pavličević, J.; Sinadinović-Fišer, S.; Špírková, M.; Budinski-Simendić, J.; Borota, O.; Janković, M.; Knez, Ž. The Phase Structure of Novel Polycarbonate-based PolyurethaneOrganoclay Nanocomposites. Adv. Mat. Res. 2012, 560-561, 771.

(51) Chen, T. K; Tien, Y. I.; Wei, K. H. Synthesis and Characterization of Novel Segmented Polyurethane/Clay Nanocomposites. Polymer 2000, 41, 1345.

(52) Seymour, R. W; Ester, G. M; Cooper, S. L. Infrared Studies of Segmented Polyurethane Elastomers. I. Hydrogen Bonding. Macromolecules 1970, 3, 579.

(53) Breßler, I.; Kohlbrecher, J.; Thünemann, A. F. SASfit: a Tool for Small-Angle Scattering Data Analysis Using a Library of Analytical Expressions. J. Appl. Cryst. 2015, 48, 1587.

(54) da Silva, G. R.; da Silva-Cunha Jr, A.; Behar-Cohen, F.; Ayres, E.; Oréfice, R. L. Biodegradable Polyurethane Nanocomposites Containing Dexamethasone for Ocular Route, Mat. Sci. Eng. C 2011, 31, 414.

(55) da Silva, G. R.; da Silva-Cunha Jr, A.; Behar-Cohen, F.; Ayres, E.; Oréfice, R. L. Biodegradation of Polyurethanes and Nanocomposites to Non-Cytotoxic Degradation Products, Polym. Degrad. Stabil. 2010, 95, 491.

(56) Wang, K.; Chen, L.; Wu, J.; Toh, M. L.; He, C.; Yee, A. F. Epoxy Nanocomposites with Highly Exfoliated Clay: Mechanical Properties and Fracture Mechanisms, Macromolecules 2005, 38,788 .

(57) Pavlićević, J.; Špírková, M.; Bera, O.; Jovičić, M.; Pilić, B.; Baloš, S.; Budinski-Simendić, J. The Influence of $\mathrm{ZnO}$ Nanoparticles on Thermal and Mechanical Behavior of Polycarbonatebased Polyurethane Composites, Composites: Part B 2014, 60, 673.

(58) Nikolić, M.; Đorđević, N.; Rogan, J.; Djonlagić, J. Influence of Clay Organic Modifier on the Morphology and Performance of Poly(E-caprolactone)/Clay Nanocomposites. J. Serb. Chem. Soc. 2015, 80, 529 . 
(59) Van Krevelen D. W. Properties of Polymers. Amsterdam: Elsevier, 1990.

(60) Strankowski, M.; Strankowska, J.; Gazda, M.; Piszczyk, Ł.; Nowaczyk, G.; Jurga, S. Thermoplastic Polyurethane/(Organically Modified Montmorillonite) Nanocomposites Produced by In Situ Polymerization, eXpress Polym. Lett. 2012, 6, 610.

(61) Leszczyńska, A.; Njuguna, J.; Pielichowski, K.; Banerjee, J. R. Polymer/Montmorillonite Nanocomposites with Improved Thermal Properties: Part I. Factors Influencing Thermal Stability and Mechanisms of Thermal Stability Improvement. Thermochim. Acta 2007, 453, 75.

(62) Park, S. -J.; Jin, F. -L. Thermal Stabilities and Dynamic Mechanical Properties of SulfoneContaining Epoxy Resin Cured with Anhydride. Polym. Degrad. Stabil. 2004, 86, 515.

(63) Jin, F. -L.; Park, S. -J. Thermal Properties of Epoxy Resin/Filler Hybrid Composites. Polym. Degrad. Stabil. 2012, 97, 2148.

(64) Špírková, M.; Poreba, R.; Brožova, L. The Influence of the Size, Shape and Character of Nanofillers on Functional Properties of Polyurethane Elastomers. In Nanocomposites, Nova Science Publishers, Inc. 2013, chapter 11, p 259.

(65) Choi, T.; Weksler, J.; Padsalgikar, A.; Runt, J. Microstructural Organization of Polydimethylsiloxane Soft Segment Polyurethanes Derived from a Single Macrodiol. Polymer 2010, 51, 4375.

(66) Hernandez, R.; Weksler, J.; Padsalgikar, A.; Runt, J. Microstructural Organization of ThreePhase Polydimethylsiloxane-based Segmented Polyurethanes. Macromolecules 2007, 40, 5441.

(67) Yasmin, A.; Luo, J. J.; Abot, J. L.; Daniel, I. M. Mechanical and Thermal Behavior of Clay/Epoxy Nanocomposites. Compos. Sci. Technol. 2006, 66, 2415.

(68) Abacha, N.; Kubouchi, M.; Sakai, T. Diffusion Behavior of Water in Polyamide 6 Organoclay Nanocomposites. eXPRESS Polym. Lett. 2009, 3, 245.

(69) Muppala, R.; Jewrajka, S. K. Properties and Applications of Poly(dimethylsiloxane) Containing Poly(meth)acrylate-based Thermoplastic Elastomer/Clay Nanocomposites. Ind. Eng. Chem. Res. 2012, 51, 15942. 
Table 1. SAXS Scattering Data of TPU-NCs Processed by the Mathematical Model

\begin{tabular}{|c|c|c|c|c|}
\hline Material & $q_{1}^{\text {a) }}$ & $a_{1}^{\text {a) }}$ & $q_{2}^{\text {a) }}$ & $q_{3}{ }^{a)}$ \\
\hline TPU-NC3 & 0.56 & 8 & 1.62 & - \\
\hline TPU-NC5 & 0.52 & 10 & 1.86 & - \\
\hline TPU-NC8 & 0.50 & 15 & 1.83 & 3.7 \\
\hline TPU-NC10 & 0.44 & 16 & 1.86 & - \\
\hline
\end{tabular}

Table 2. Surface Roughness of Pure TPU and TPU-NCs

\begin{tabular}{cccccc}
\hline Material & $\begin{array}{c}\text { Organoclay } \\
\text { loadings } \\
(\mathrm{wt} \%)\end{array}$ & $\begin{array}{c}\text { Surface area } \\
\left(\mu \mathrm{m}^{2}\right)\end{array}$ & $R_{\mathrm{q}}{ }^{*}(\mathrm{~nm})$ & $R_{\mathrm{a}}{ }^{* *}(\mathrm{~nm})$ & $R_{\max }{ }^{* * *}(\mathrm{~nm})$ \\
\hline TPU-NC0 & 0 & 4.1 & 9.2 & 7.5 & 58 \\
TPU-NC1 & 1 & 4.5 & 92.1 & 73.9 & 437 \\
TPU-NC3 & 3 & 4.4 & 62.0 & 50.6 & 382 \\
TPU-NC5 & 5 & 4.6 & 53.9 & 42.5 & 319 \\
TPU-NC8 & 8 & 4.8 & 93.6 & 74.2 & 644 \\
TPU-NC10 & 10 & 4.2 & 30.5 & 23.3 & 234 \\
\hline
\end{tabular}

Surface area: the total area of examined material surface (the three-dimensioned area of a given region expressed as the sum of the area of all the triangles formed by three adjacent data points); $R_{\mathrm{q}}^{*}(\mathrm{rms})$ : the standard deviation of the $\mathrm{Z}$ values within the given area; $R_{\mathrm{a}}^{* *}$ (mean roughness): the mean value of the surface relative to the center place; $R_{\max }{ }^{* *}$ (max height): the difference in height between the highest and lowest points on the surface relative to the mean plane; mean: the average of all $\mathrm{Z}$ values within the enclosed area. 
Table 3. DSC and TGA Results for Pure TPU, TPU-NCs and TPU/C30B-10

\begin{tabular}{|c|c|c|c|c|c|c|c|c|c|}
\hline Material & $\begin{array}{l}T_{\mathrm{gHS}}{ }^{\mathrm{a}} \\
\left({ }^{\circ} \mathrm{C}\right)\end{array}$ & $\begin{array}{c}T_{\mathrm{mHS}}{ }^{\mathrm{b}} \\
\left({ }^{\circ} \mathrm{C}\right)\end{array}$ & $\begin{array}{l}\Delta H_{\mathrm{m}}{ }^{\mathrm{c}} \\
(\mathrm{J} / \mathrm{g})\end{array}$ & $\begin{array}{l}T_{\mathrm{cHS}}{ }^{\mathrm{d}} \\
\left({ }^{\circ} \mathrm{C}\right)\end{array}$ & $\begin{array}{l}\Delta H_{\mathrm{c}}^{\mathrm{e}} \\
(\mathrm{J} / \mathrm{g})\end{array}$ & $\begin{array}{c}X_{\mathrm{c}}^{\mathrm{HS}} \\
(\%)\end{array}$ & $\begin{array}{l}T_{10 \%} \% \\
\left({ }^{\circ} \mathrm{C}\right)\end{array}$ & $T_{\max }\left({ }^{\circ} \mathrm{C}\right)$ & $\begin{array}{c}\text { Residue } \\
\text { yield }^{\mathrm{f}} \text { at } \\
650{ }^{\circ} \mathrm{C} \\
(\%)\end{array}$ \\
\hline TPU-NC0 & 32 & 157 & 3.9 & 84 & 5.1 & 19 & 293 & $313 / 338 / 530$ & 2.7 \\
\hline TPU-NC1 & 15 & 169 & 3.6 & 129 & 6.6 & 18 & 309 & $322 / 437 / 464$ & 4.8 \\
\hline TPU-NC3 & 21 & 166 & 3.4 & 143 & 4.6 & 17 & 308 & $331 / 461 / 524$ & 6.6 \\
\hline TPU-NC5 & 30 & 185 & 2.8 & 146 & 1.2 & 14 & 305 & $352 / 457 / 524$ & 8.7 \\
\hline TPU-NC8 & 29 & 182 & 3.0 & 150 & 0.3 & 15 & 281 & $332 / 462 / 523$ & 10.9 \\
\hline TPU-NC10 & 28 & 186 & 3.3 & 144 & 0.4 & 17 & 269 & $332 / 464 / 526$ & 12.7 \\
\hline TPU/C30B-10 & 24 & 165 & 3.5 & 142 & 0.6 & 18 & 257 & $321 / 458 / 517$ & 11.9 \\
\hline
\end{tabular}

${ }^{a}$ Glass transition temperature of hard segment; Determined as inflexion point between two tangents.

${ }^{\mathrm{b}}$ Melting temperature of hard segment; Determined as the temperature of the minimum of the endothermic peak in DSC thermograms.

${ }^{\mathrm{c}}$ Enthalpy of melting; Determined by integration on the endothermic peak on the DSC thermograms.

${ }^{\mathrm{d}}$ Temperature of crystallization of hard segment.

${ }^{\mathrm{e}}$ Enthalpy of crystallization; Determined by integration on the exothermic peak on the DSC thermograms.

${ }^{\mathrm{f}}$ Residual yield of TPU-NCs are in relatively good agreement with targeted organoclay content, especially for materials with higher organoclay content, due to the greater accuracy of the TG method. 
Table 4. DMTA Results for Pure TPU and TPU-NCs

\begin{tabular}{cccccc}
\hline Material & $\begin{array}{c}G^{\prime} \text { at } 25^{\circ} \mathrm{C} \\
(\mathrm{Pa})\end{array}$ & $\begin{array}{c}T_{\mathrm{gPDMS}}{ }^{\tan \delta} \\
\left({ }^{\circ} \mathrm{C}\right)\end{array}$ & $\begin{array}{c}T \alpha_{2}{ }^{\tan \delta} \\
\left({ }^{\circ} \mathrm{C}\right)\end{array}$ & $\begin{array}{c}T_{\mathrm{gHS}} \tan \delta \\
\left({ }^{\circ} \mathrm{C}\right)\end{array}$ & $\begin{array}{c}T_{\mathrm{mHS}}{ }^{\tan \delta} \\
\left({ }^{\circ} \mathrm{C}\right)\end{array}$ \\
\hline TPU-NC0 & $3.8 \times 10^{7}$ & -102 & -2 & 74 & 140 \\
TPU-NC1 & $4.1 \times 10^{7}$ & -104 & 2 & 86 & 142 \\
TPU-NC3 & $3.9 \times 10^{7}$ & -104 & 4 & 90 & 150 \\
TPU-NC5 & $8.0 \times 10^{7}$ & -104 & 4 & 93 & 155 \\
TPU-NC8 & $6.8 \times 10^{7}$ & -110 & 3 & 93 & 202 \\
\hline
\end{tabular}




\section{Figure Captions}

Figure 1. (a) The structure of thermoplastic polyurethane based on EO-PDMS as soft segment and MDI-BD as hard segment and (b) the organoclay modifier, methyl-tallow-bis-2-hydroxyethyl quaternary ammonium salt, $\mathrm{T}$ is tallow ( $\sim 65 \% \mathrm{C} 18, \sim 30 \% \mathrm{C} 16, \sim 5 \% \mathrm{C} 14)$.

Figure 2. FTIR spectra of (a) organoclay (C30B), control TPU/C30B-10 *, pure TPU; (b) TPUNCs with variable organoclay content and (c) enlarged region from $2500-4000 \mathrm{~cm}^{-1}$ for selected samples. * Control TPU-C30B-10 with $10 \mathrm{wt} \%$ of C30B was prepared as TPU-NC10 but C30B was added at the end of reaction.

Figure 3. SWAXS profiles of pure TPU, Cloisite 30B and selected TPU-NCs.

Figure 4. SEM images of pure TPU and TPU-NCs at magnification 3000x.

Figure 5. (a) 3D height and (b) 2D phase AFM images of pure TPU and TPU-NCs.

Figure 6. DSC curves of pure TPU, TPU-NCs and TPU/C30B-10 obtained during the second heating (a) and cooling (b) run.

Figure 7. (a) TGA and (b) DTG thermograms of organoclay (C30B), pure TPU, TPU-NCs and TPU/C30B-10 obtained under nitrogen atmosphere.

Figure 8. (a) Storage modulus and (b) tan $\delta$ of pure TPU and TPU-NCs versus temperature.

Figure 9. Contact angles of pure TPU, TPU-NCs and TPU/C30B-10.

Figure 10. (a) Surface free energy and its components; b) surface free energy parameters of pure TPU, TPU-NCs and TPU/C30B-10. 
a)

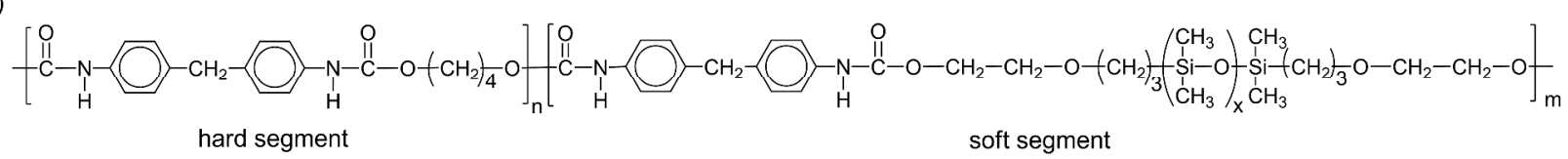
b)<smiles>[3H][N+](C)(CCO)CCO</smiles>

\section{Figure 1.}
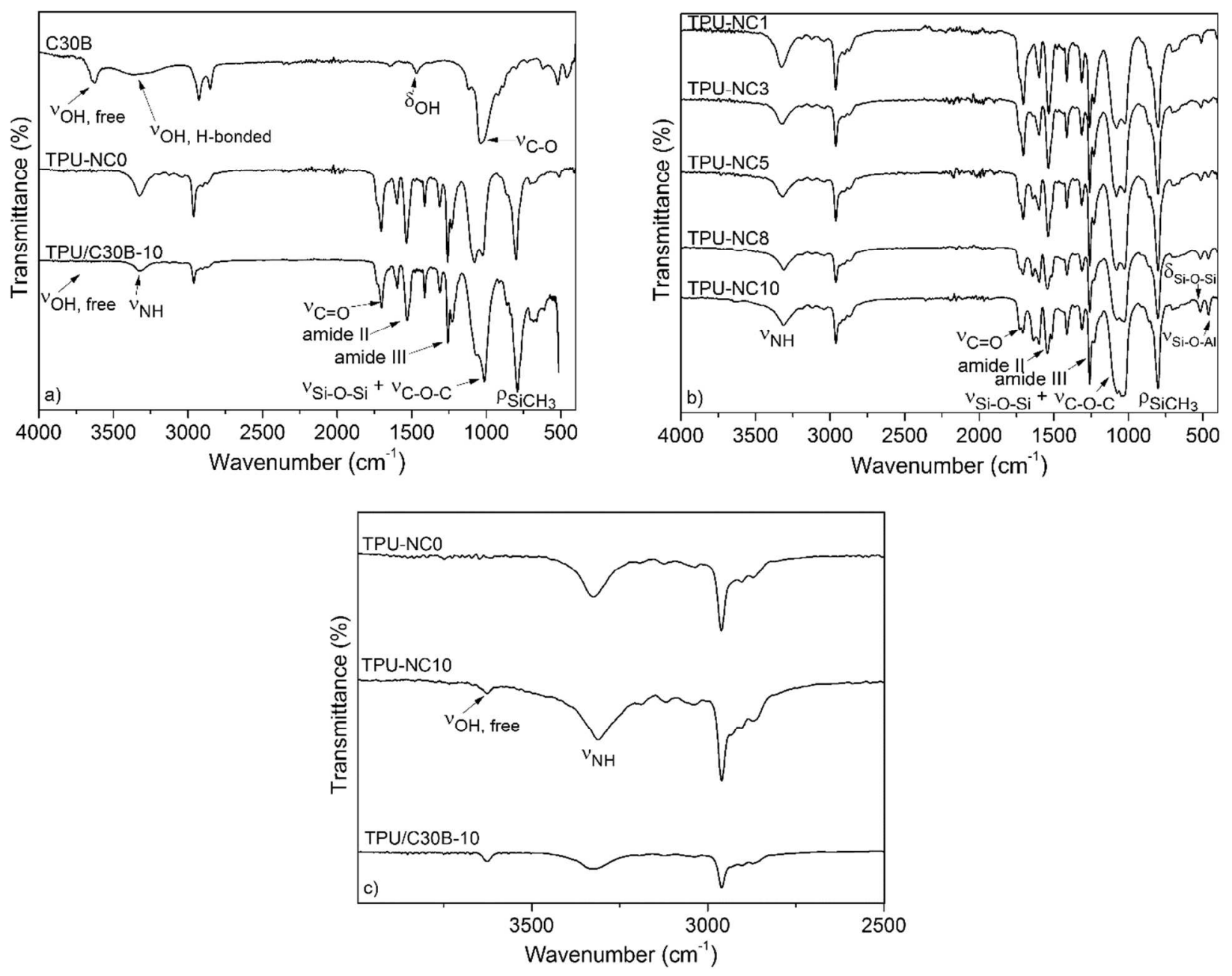

Figure 2. 


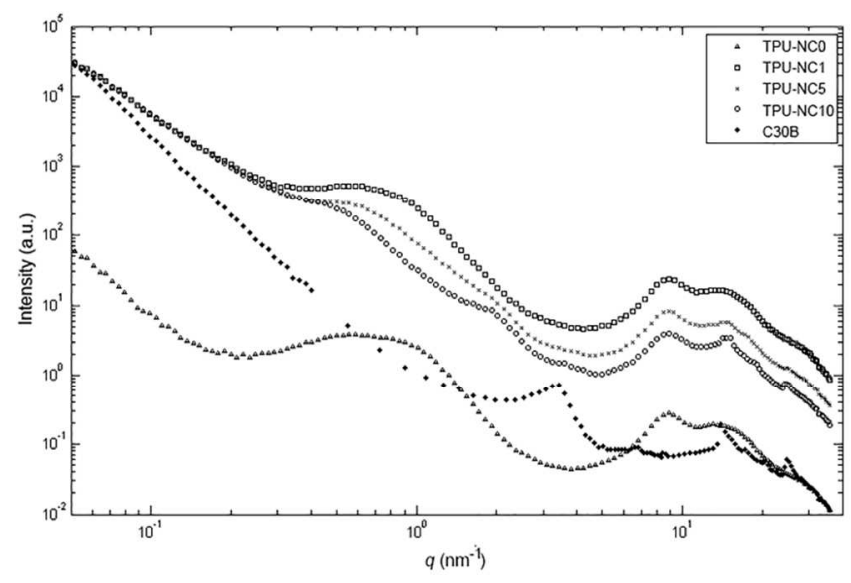

Figure 3. 


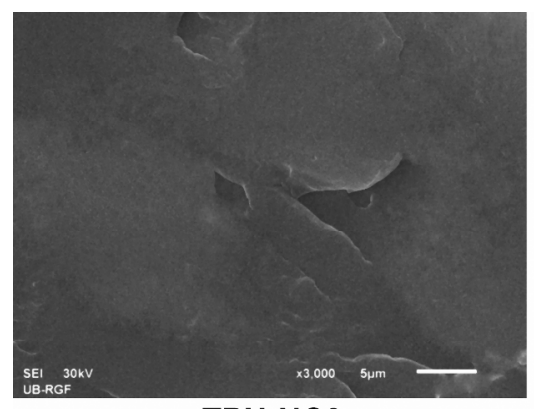

TPU-NCO

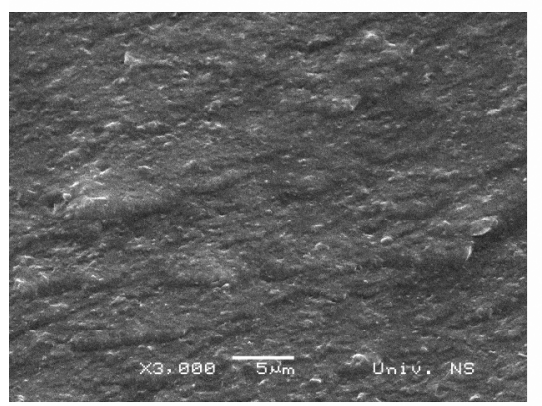

TPU-NC5

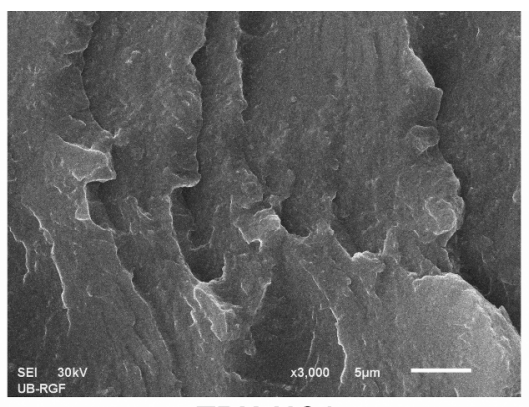

TPU-NC1

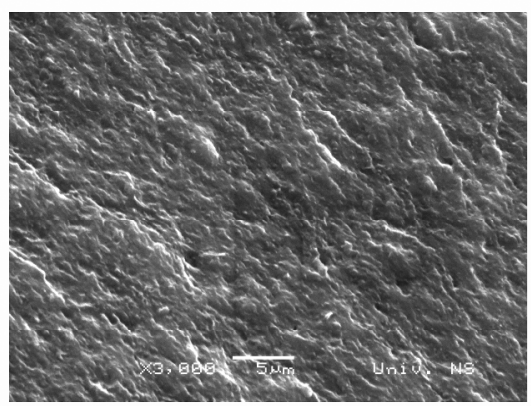

TPU-NC8

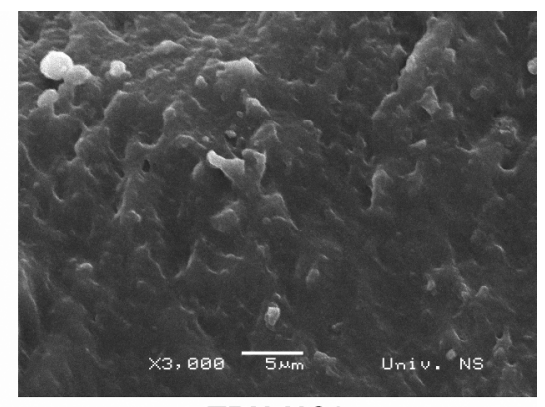

TPU-NC3

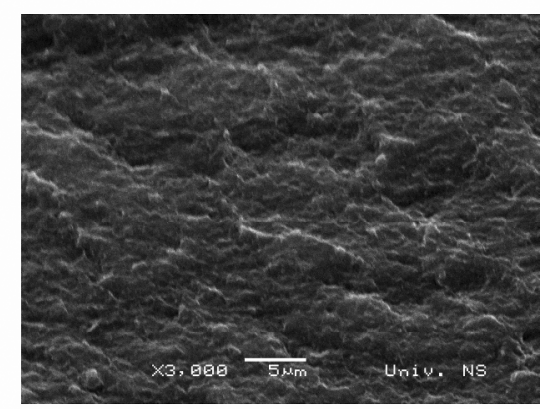

TPU-NC10

\section{Figure 4.}




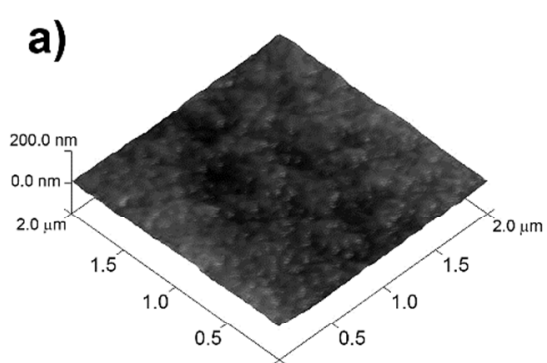

TPU-NC0

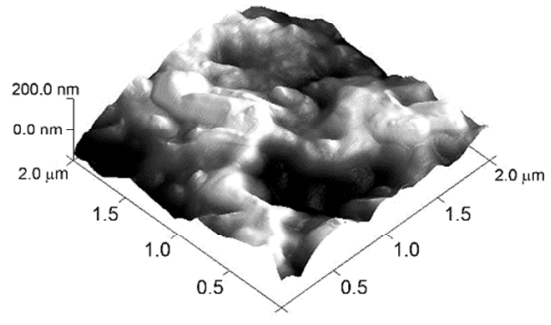

TPU-NC5

b)
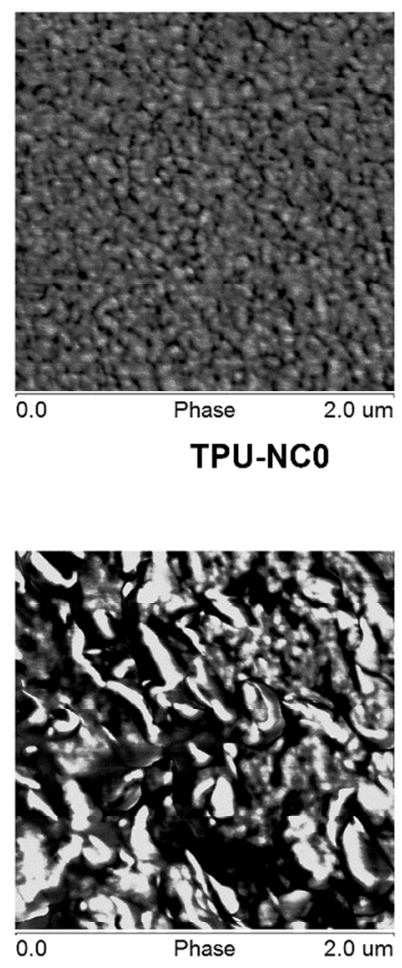

TPU-NC5

$50.0^{\circ}$

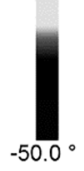

$-50.0^{\circ}$

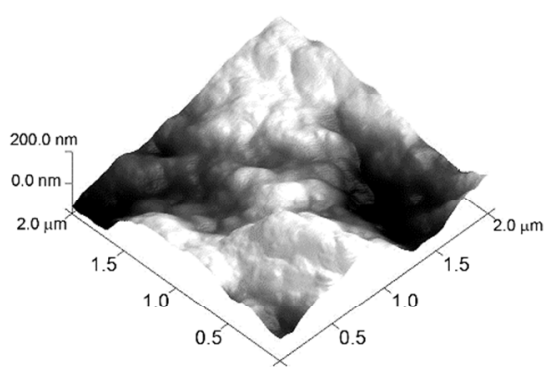

TPU-NC1
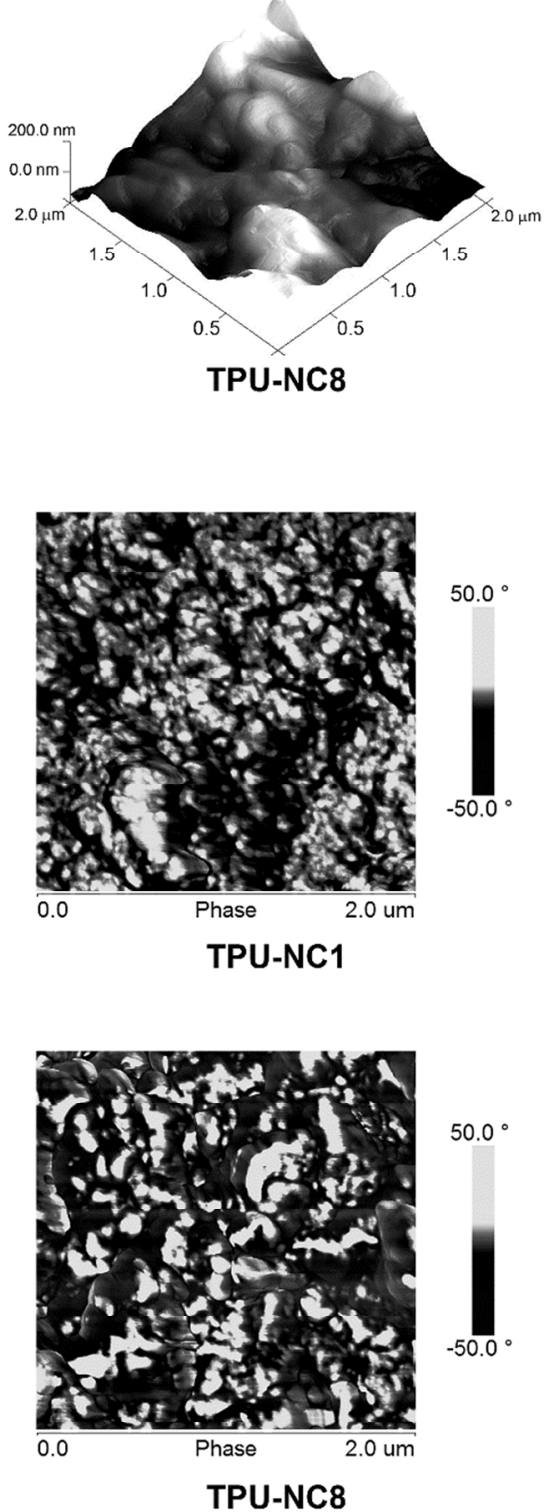

$50.0^{\circ}$

Figure 5.

TPU-NC8

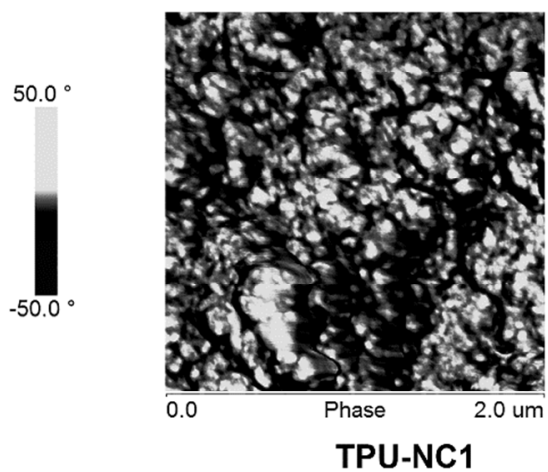

TPU-NC1

$50.0^{\circ}$

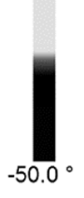

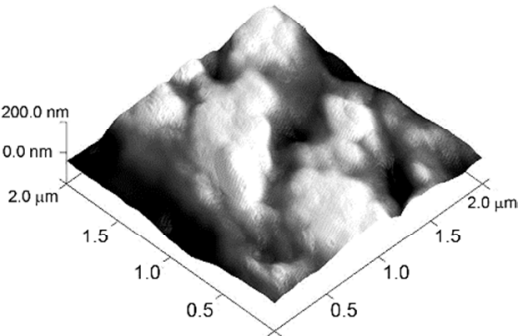

TPU-NC10

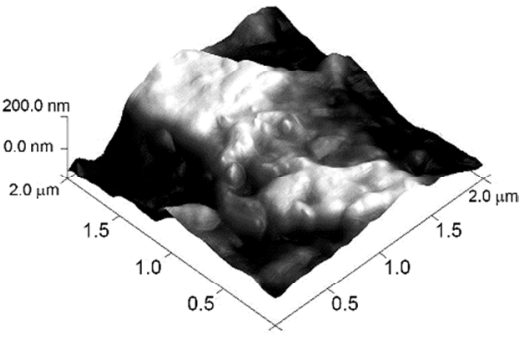

TPU-NC3
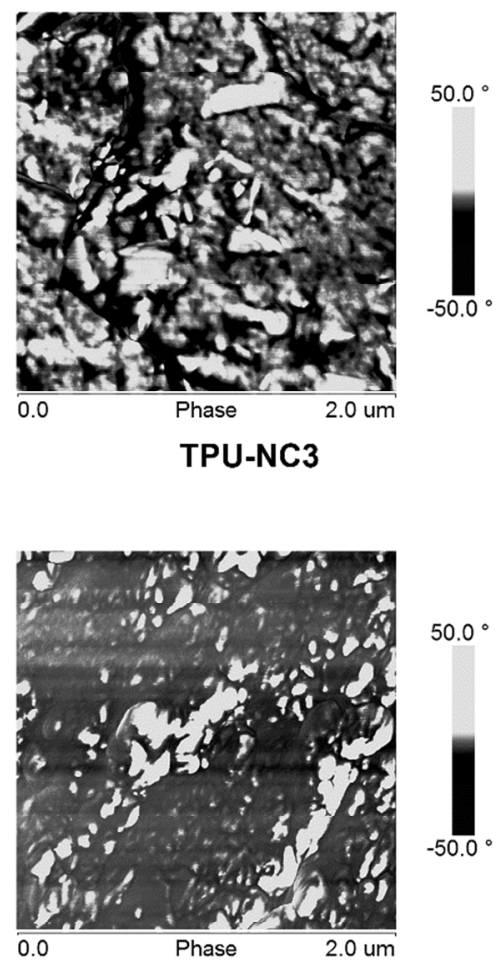

TPU-NC10 

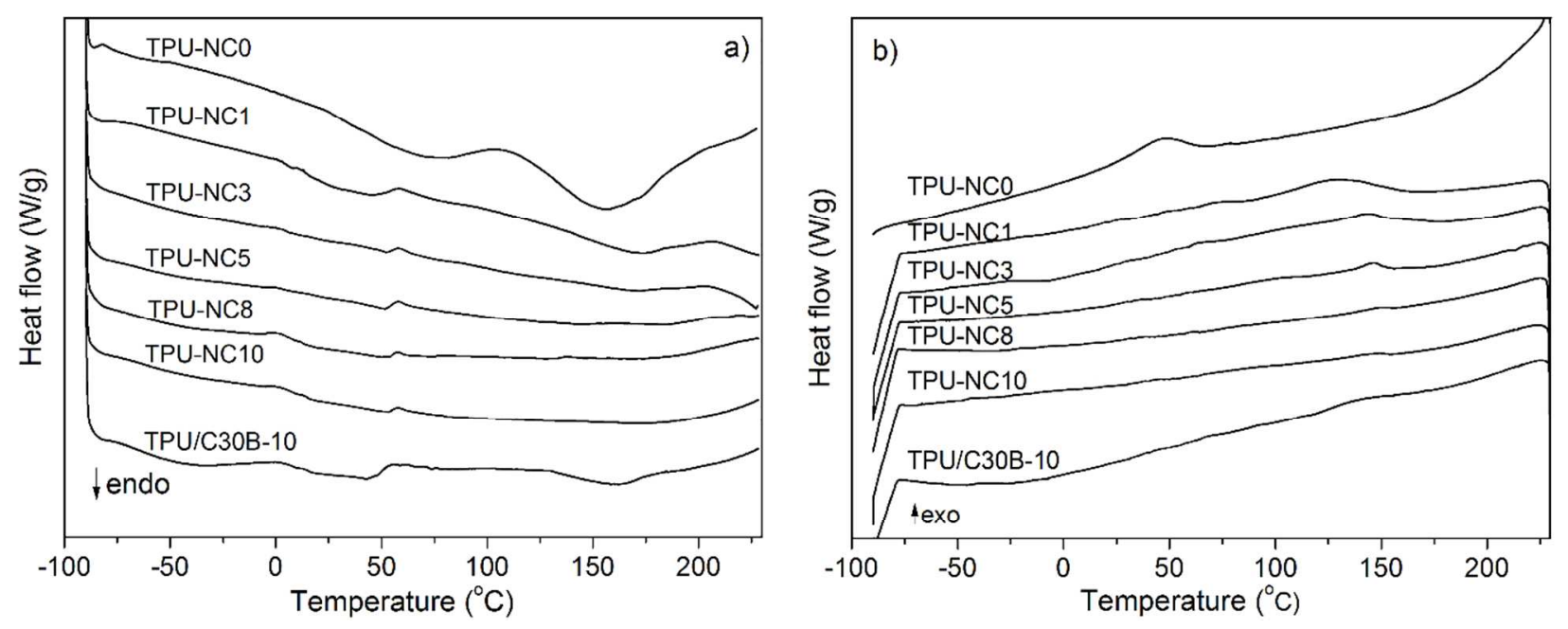

\section{Figure 6.}
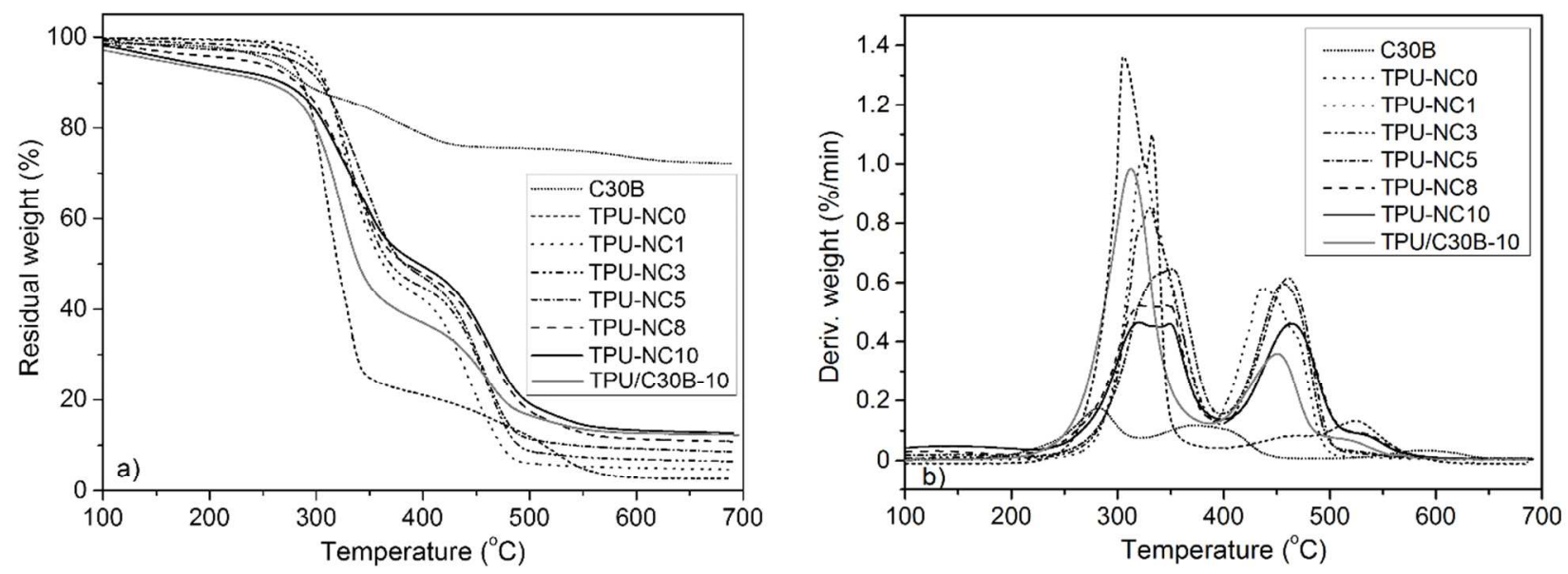

\section{Figure 7.}
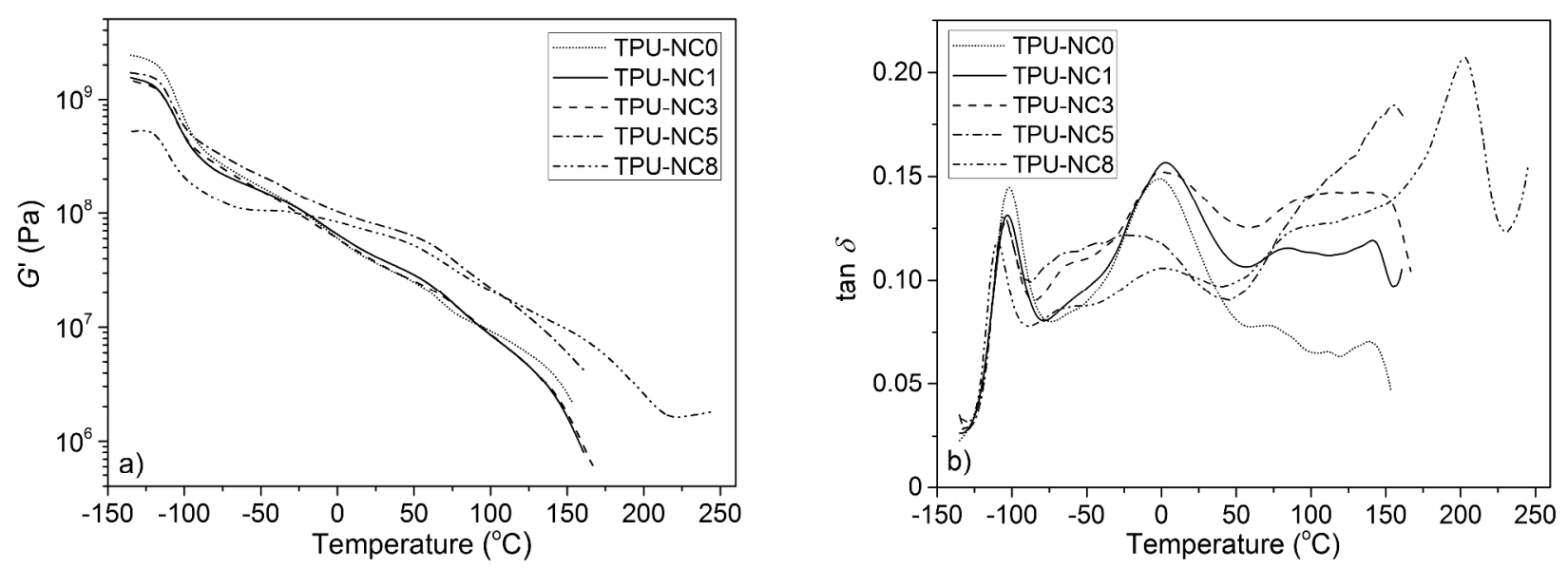

Figure 8. 


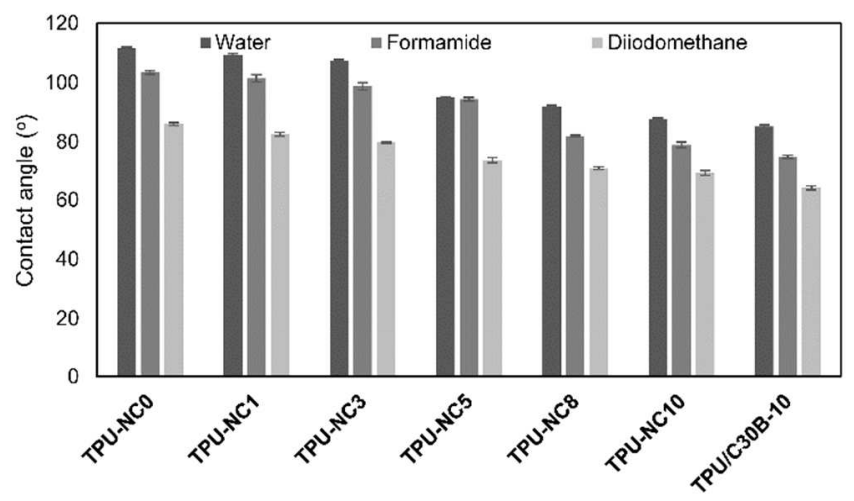

Figure 9.
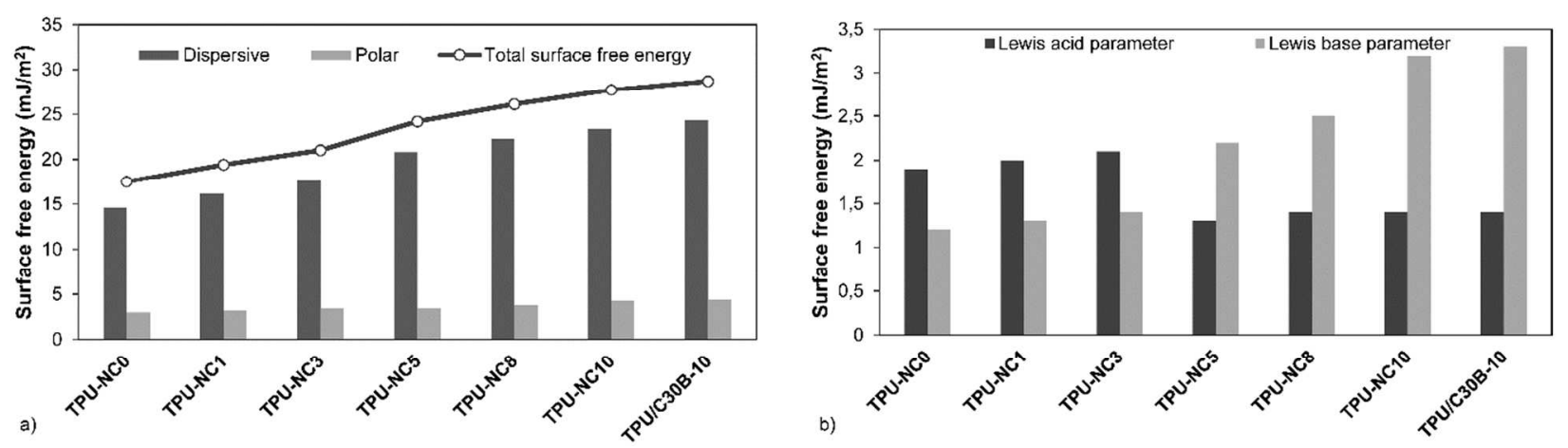

Figure 10.

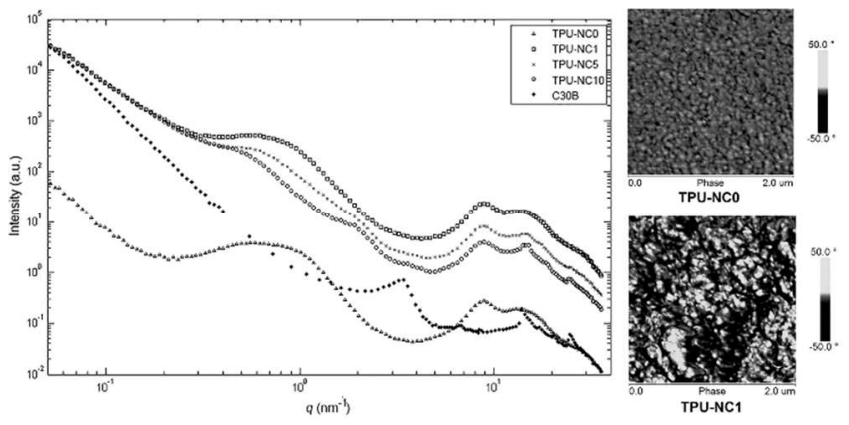

For Table of Contents Only 
a)

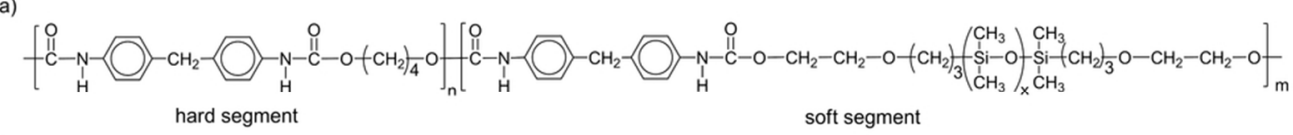

b)

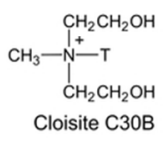

Figure 1. (a) The structure of thermoplastic polyurethane based on EO-PDMS as soft segment and MDI-BD as hard segment and (b) the organoclay modifier, methyl-tallow-bis-2-hydroxyethyl quaternary ammonium salt, $\mathrm{T}$ is tallow $(\sim 65 \% \mathrm{C} 18, \sim 30 \% \mathrm{C} 16, \sim 5 \% \mathrm{C} 14)$.

$41 \times 9 \mathrm{~mm}(600 \times 600 \mathrm{DPI})$ 

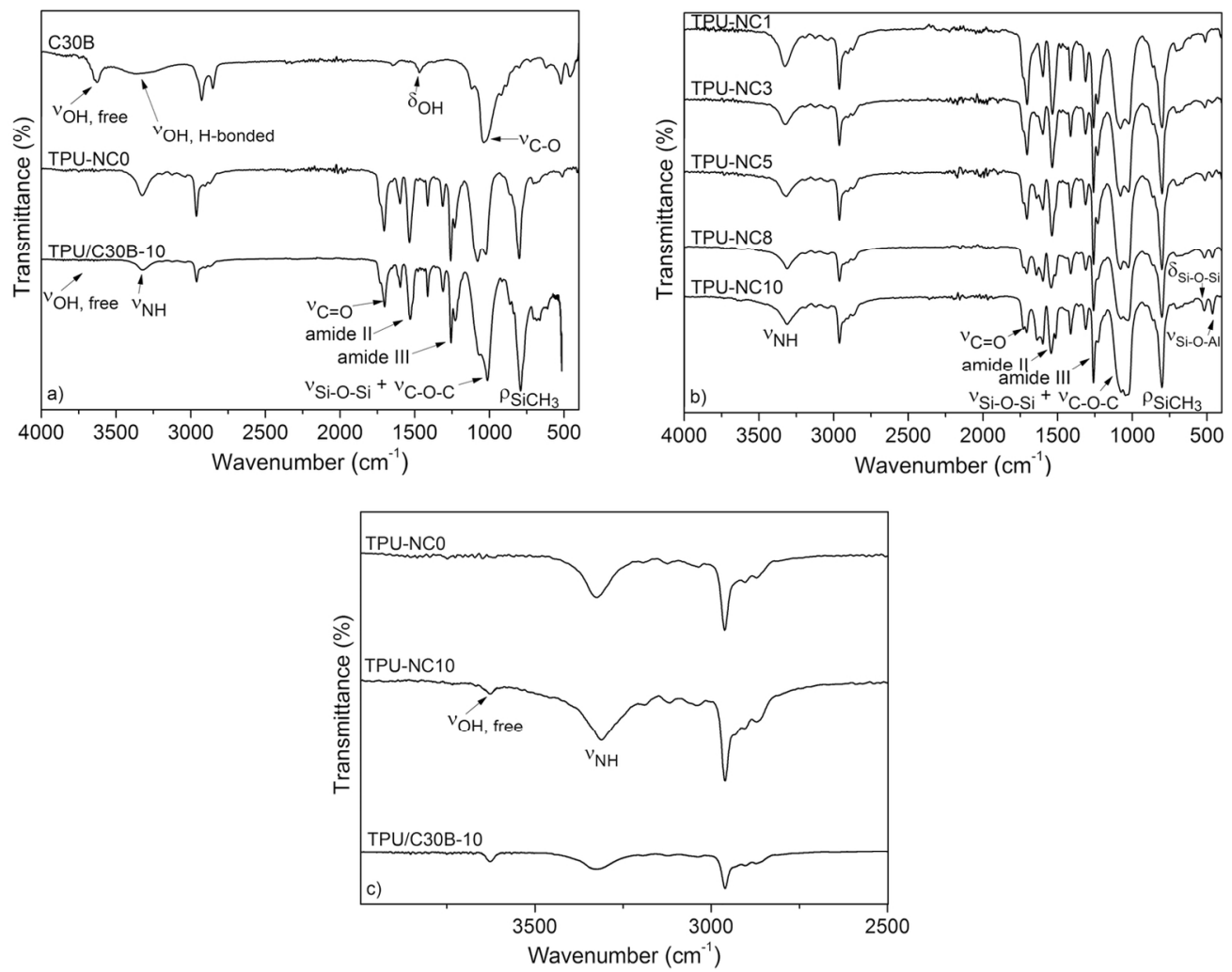

Figure 2. FTIR spectra of (a) organoclay (C30B), control TPU/C30B-10 *, pure TPU; (b) TPU-NCs with variable organoclay content and (c) enlarged region from $2500-4000 \mathrm{~cm}-1$ for selected samples. $*$ Control TPU-C30B-10 with 10 wt \% of C30B was prepared as TPU-NC10 but C30B was added at the end of reaction.

\section{$139 \times 109 \mathrm{~mm}(300 \times 300 \mathrm{DPI})$}




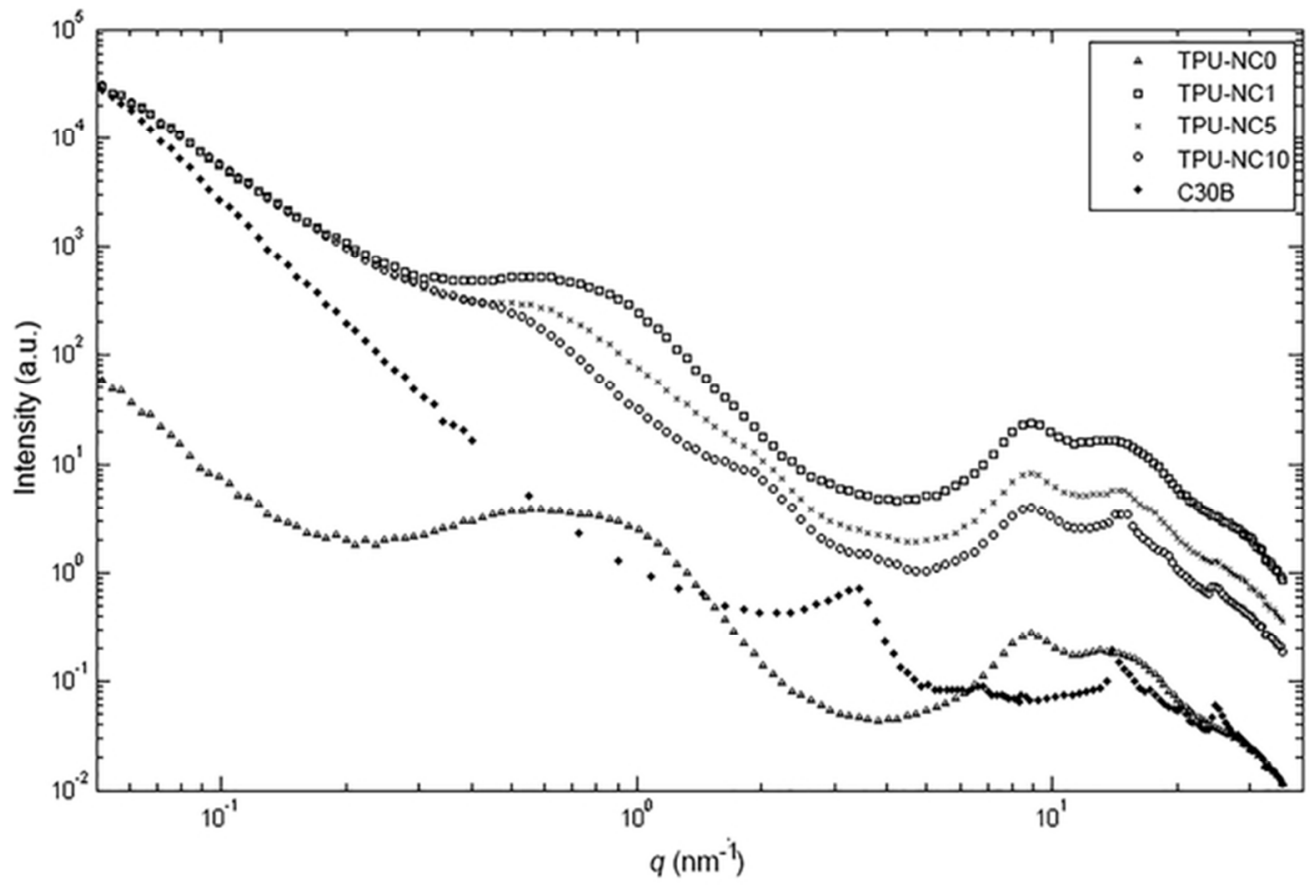

Figure 3. SWAXS profiles of pure TPU, Cloisite 30B and selected TPU-NCs.

$57 \times 38 \mathrm{~mm}(300 \times 300 \mathrm{DPI})$ 

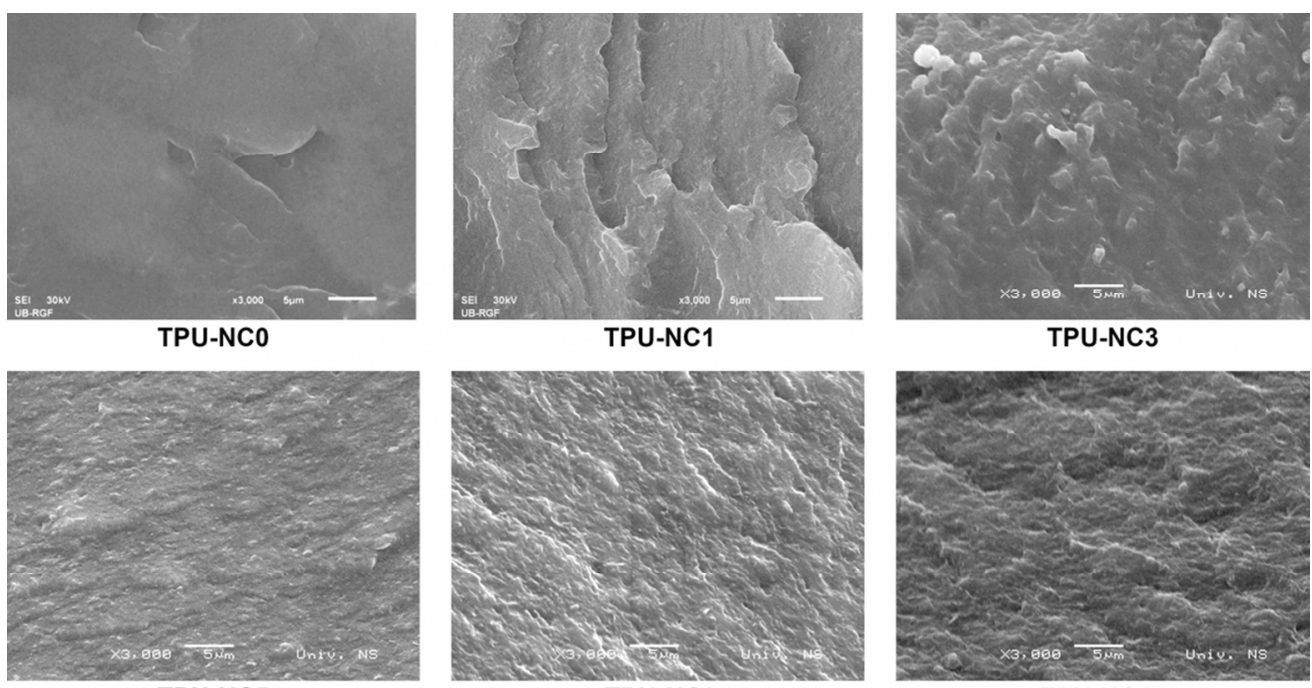

TPU-NC5

TPU-NC8

TPU-NC10

Figure 4. SEM images of pure TPU and TPU-NCs at magnification 3000x.

$$
95 \times 51 \mathrm{~mm}(300 \times 300 \mathrm{DPI})
$$




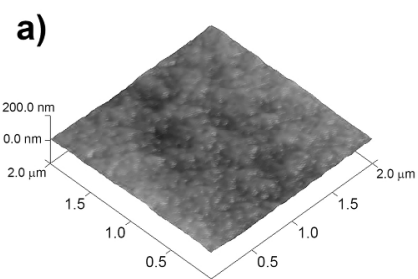

TPU-NCO

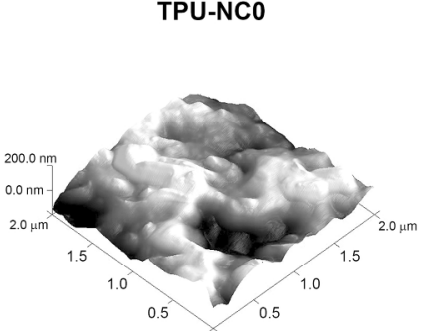

TPU-NC5

b)
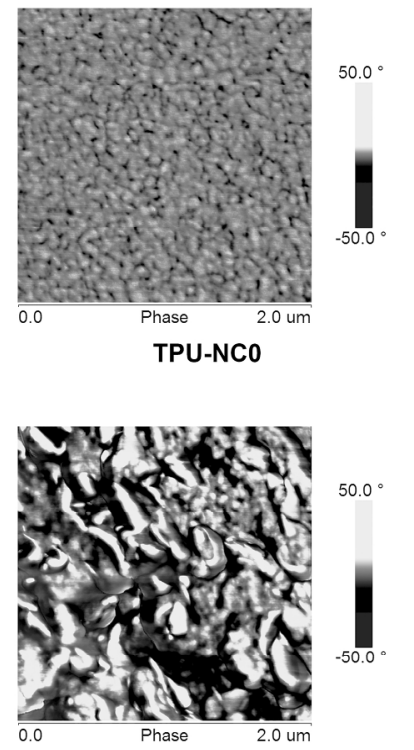

TPU-NC5

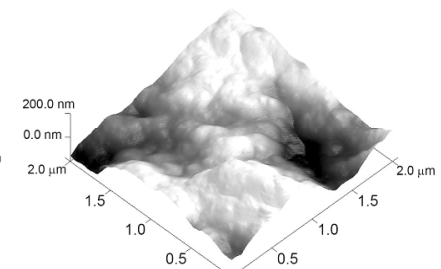

TPU-NC1

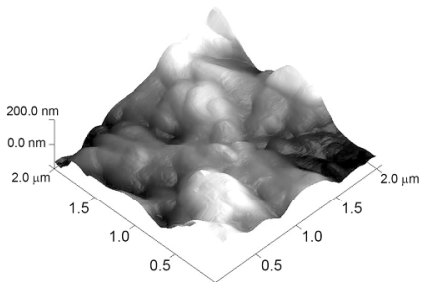

TPU-NC8
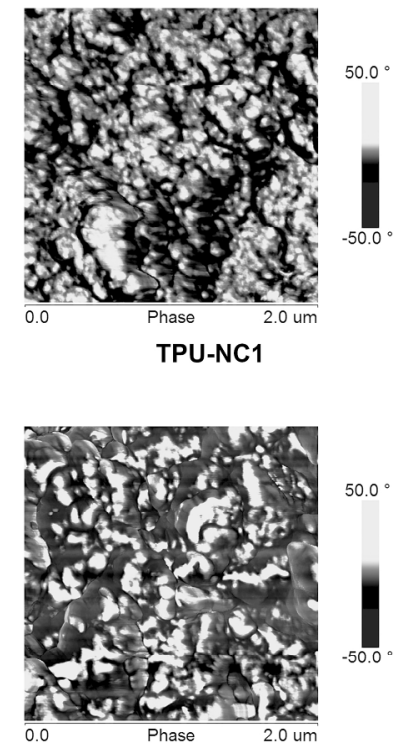

TPU-NC8

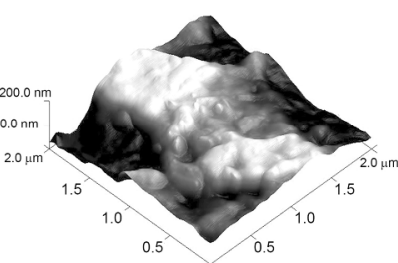

TPU-NC3

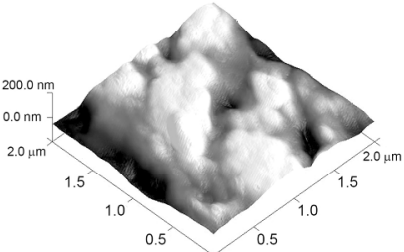

TPU-NC10
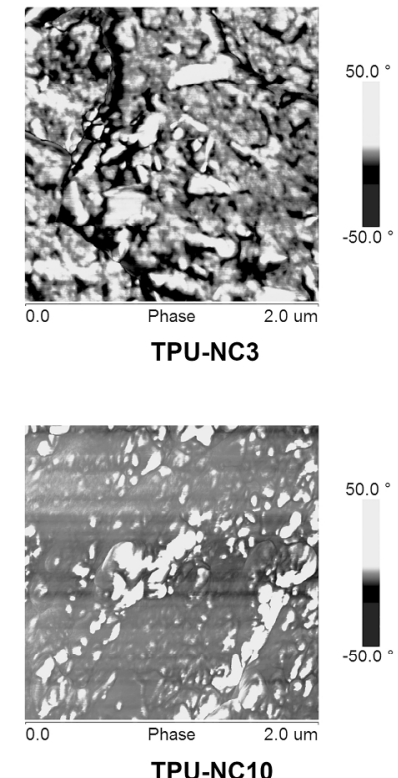

Figure 5. (a) 3D height and (b) 2D phase AFM images of pure TPU and TPU-NCs. $219 \times 270 \mathrm{~mm}(300 \times 300 \mathrm{DPI})$ 

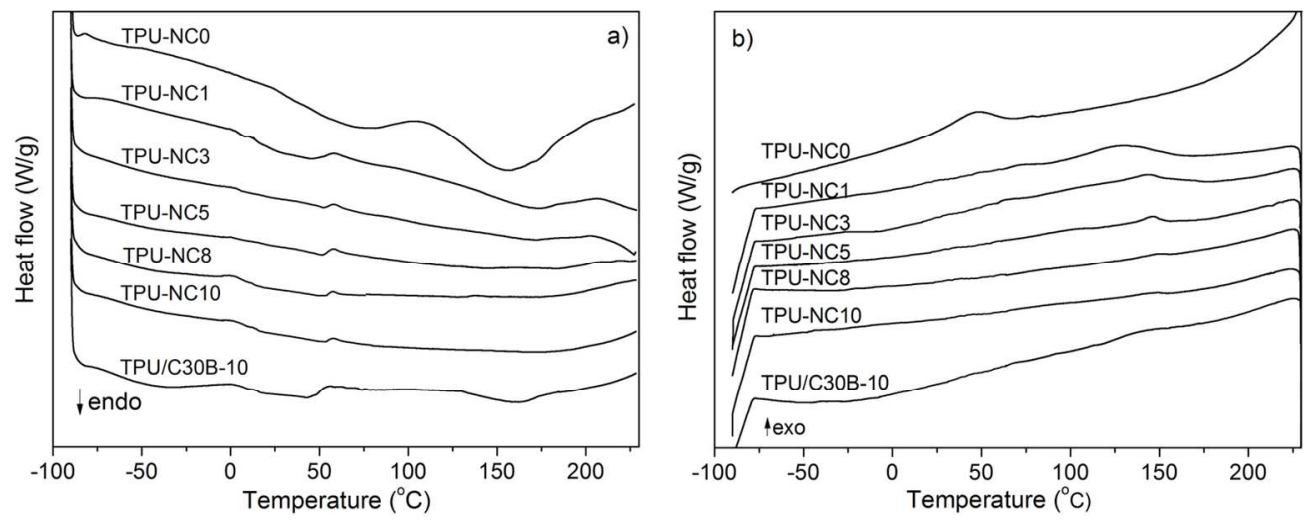

Figure 6. DSC curves of pure TPU, TPU-NCs and TPU/C30B-10 obtained during the second heating (a) and cooling (b) run.

$68 \times 26 \mathrm{~mm}(600 \times 600 \mathrm{DPI})$ 

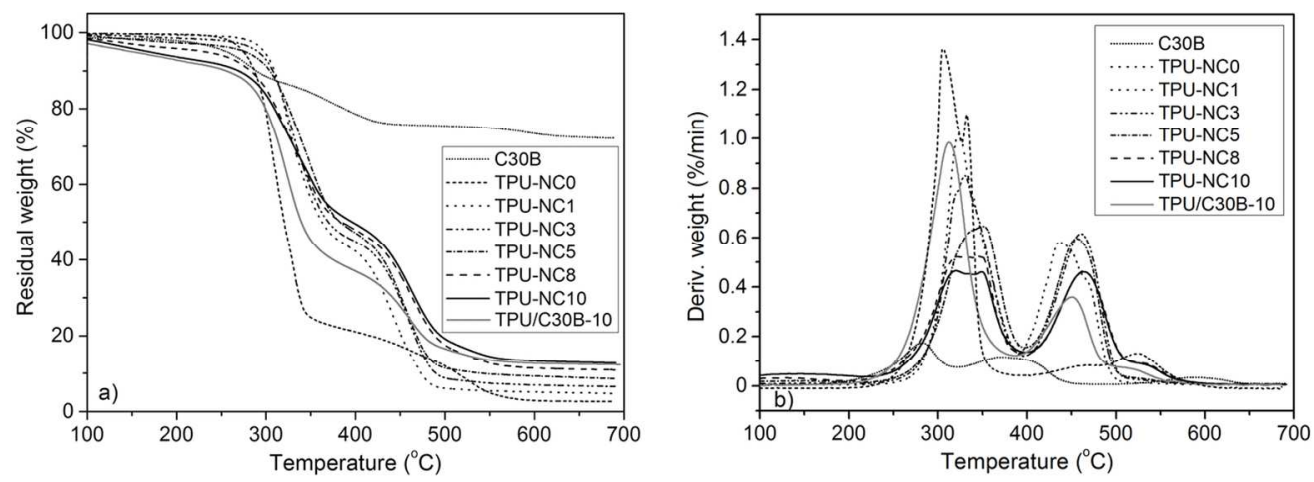

Figure 7. (a) TGA and (b) DTG thermograms of organoclay (C30B), pure TPU, TPU-NCs and TPU/C30B-10 obtained under nitrogen atmosphere.

\section{$62 \times 22 \mathrm{~mm}(600 \times 600 \mathrm{DPI})$}



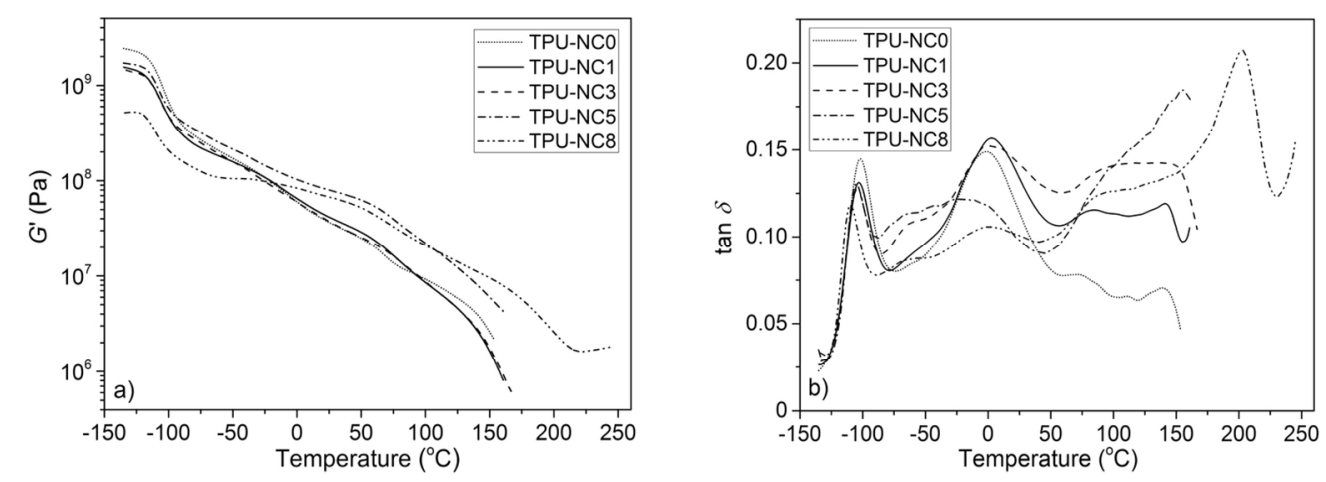

Figure 8. (a) Storage modulus and (b) $\tan \delta$ of pure TPU and TPU-NCs versus temperature.

$62 \times 21 \mathrm{~mm}(600 \times 600 \mathrm{DPI})$ 


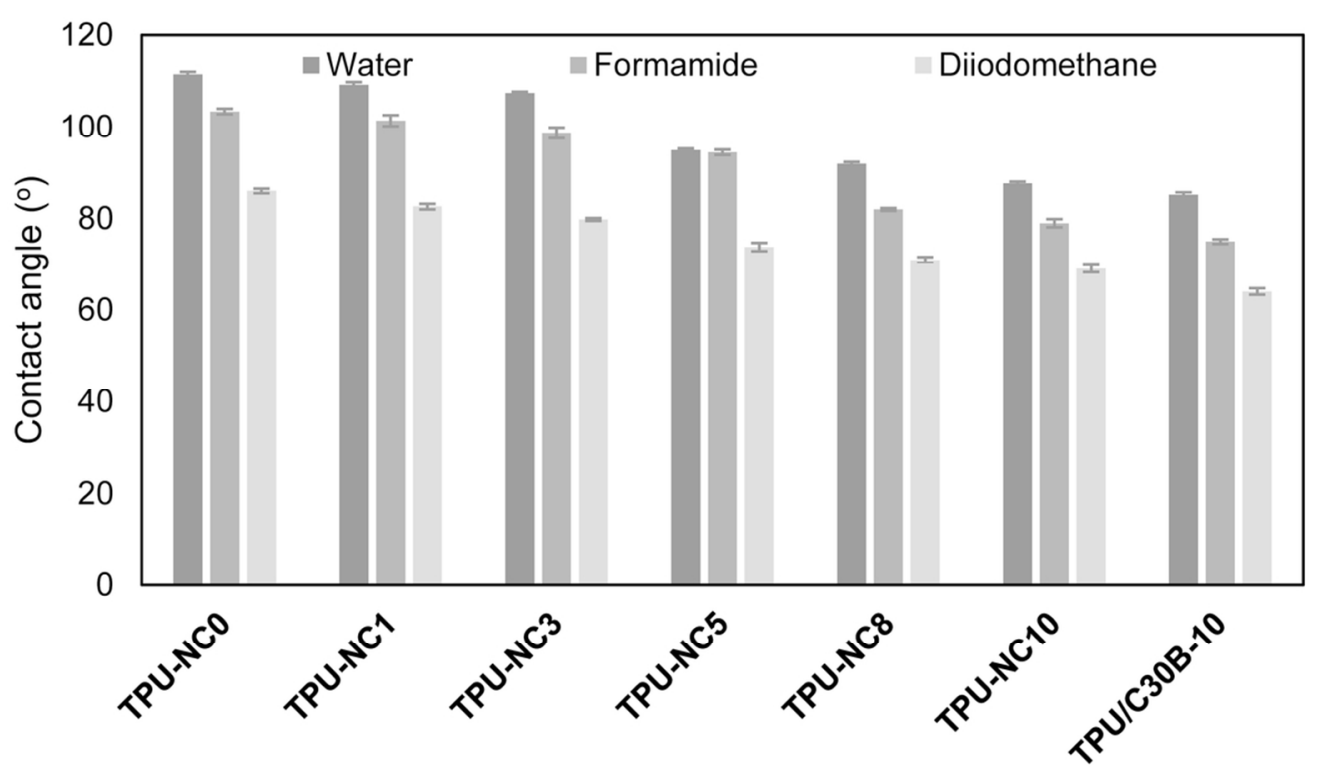

Figure 9. Contact angles of pure TPU, TPU-NCs and TPU/C30B-10.

$49 \times 29 \mathrm{~mm}(600 \times 600 \mathrm{DPI})$ 

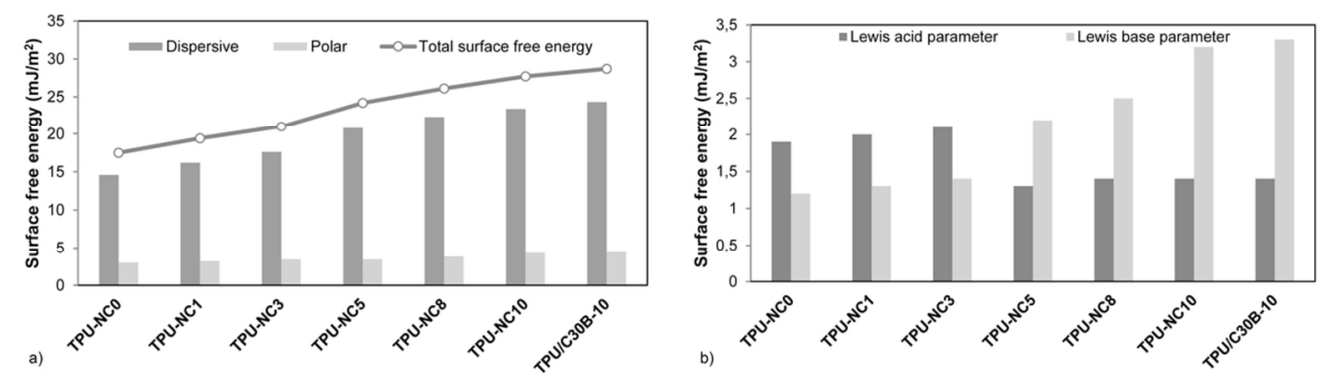

Figure 10. (a) Surface free energy and its components; b) surface free energy parameters of pure TPU, TPUNCs and TPU/C30B-10.

$49 \times 14 \mathrm{~mm}(600 \times 600 \mathrm{DPI})$ 

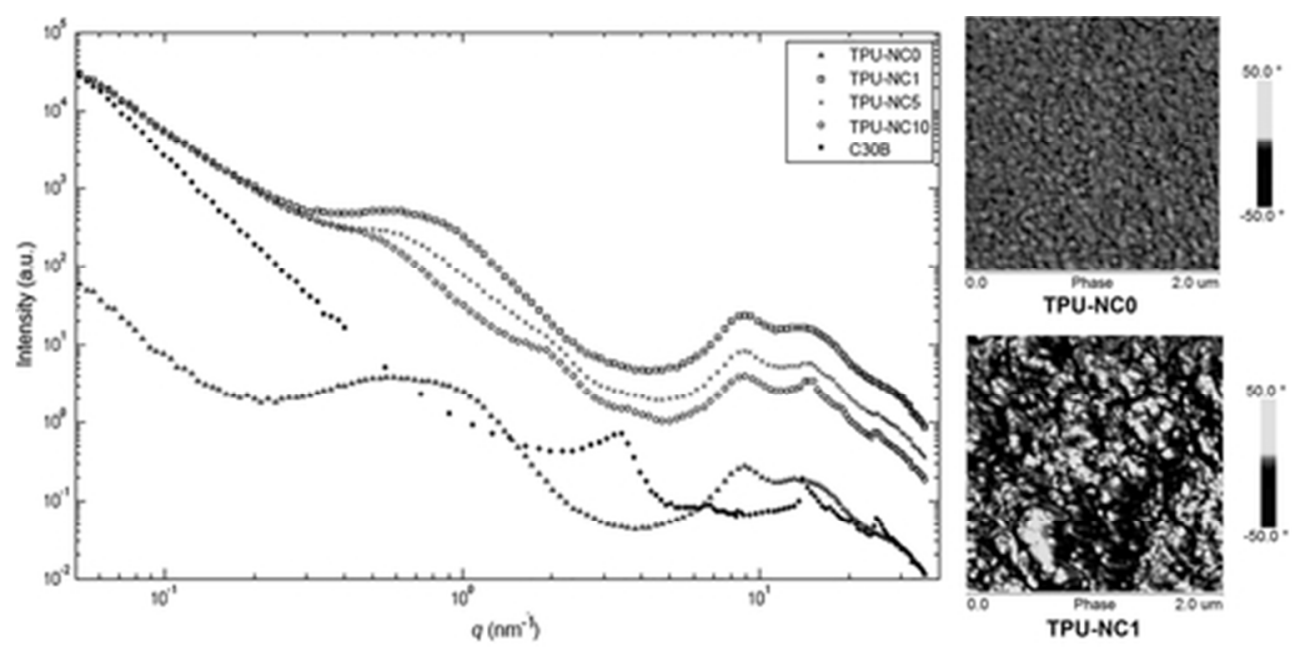

For Table of Contents Only $41 \times 20 \mathrm{~mm}(300 \times 300 \mathrm{DPI})$ 